\title{
Geographic interpretation: The role of spatial knowledge in the interpretation of natural resources
}

\author{
Heidi Leigh Bailey \\ West Virginia University
}

Follow this and additional works at: https://researchrepository.wvu.edu/etd

\section{Recommended Citation}

Bailey, Heidi Leigh, "Geographic interpretation: The role of spatial knowledge in the interpretation of natural resources" (2006). Graduate Theses, Dissertations, and Problem Reports. 2462.

https://researchrepository.wvu.edu/etd/2462

This Thesis is protected by copyright and/or related rights. It has been brought to you by the The Research Repository @ WVU with permission from the rights-holder(s). You are free to use this Thesis in any way that is permitted by the copyright and related rights legislation that applies to your use. For other uses you must obtain permission from the rights-holder(s) directly, unless additional rights are indicated by a Creative Commons license in the record and/ or on the work itself. This Thesis has been accepted for inclusion in WVU Graduate Theses, Dissertations, and Problem Reports collection by an authorized administrator of The Research Repository @ WVU. For more information, please contact researchrepository@mail.wvu.edu. 


\title{
Geographic Interpretation:
}

The Role of Spatial Knowledge in the Interpretation of Natural Resources

\author{
Heidi Leigh Bailey
}

\author{
Thesis submitted to the \\ Davis College of Agriculture, Forestry, and Consumer Sciences \\ at West Virginia University \\ in partial fulfillment of the requirements \\ for the degree of \\ Master of Science \\ in \\ Recreation, Parks and Tourism Resources
}
David Smaldone, Ph.D., Chair Robert Burns, Ph.D.
Gregory Elmes, Ph.D.
Morgantown, West Virginia 2006

Keywords: Interpretation, Geography, Resource Management, Wildland Fire, Maps, Schema, Cognitive Mapping, Spatial Knowledge, Visitor Studies 


\begin{abstract}
Geographic Interpretation:

The Role of Spatial Knowledge in the Interpretation of Natural Resources
\end{abstract}

Heidi Bailey

A surge of interest in geographic information has stemmed from the recent proliferation of Geographic Information Systems, Global Positioning Systems, and web-based tools such as Google Earth. This growing interest in geographic information has many implications for natural resource interpretation. Visitor centers and interpretive centers have long been sources of geographic information - providing maps and exhibits depicting a site or region. Such displays come in all shapes and sizes and in a variety of media, including maps, models, projections, animations and dioramas. Yet missing from the field of interpretation is research on the effectiveness of these tools in conveying geographic information to visitors.

A need for research on visitors' understanding of geographic and spatial concepts has also surfaced in the social science literature on wildland fire. Researchers have repeatedly intimated a lack of knowledge by the public regarding the size of fires. Interpretation is used as a tool to increase knowledge about fire effects and to influence attitudes towards fire policy. Using interpretation to communicate spatial concepts pertaining to fire is therefore a logical extension. The recent shift to ecosystem management has created a need to communicate to the public about the nature of landscape-level processes. This raises the question of how people perceive large landscapes and how they learn about large-scale spaces.

In the study reported in this thesis, the spatial cognition of National Forest visitors was researched through the use of a survey. Visitors to the Columbia River Gorge National Scenic Area and Mt. Hood National Forest in Oregon were sampled from March - April, 2006. These visitors were asked about their cognitive representations of forest environments and their perceptions of the size of a recent fire. Three methods were adapted from research on human cognition: schema representations, cognitive mapping, and language structure. The results revealed a significant difference between male and female perceptions of fire size and a general lack of knowledge concerning fire size for both groups.

This thesis also reviews the literature on spatial cognition and provides a theoretical and empirical basis to suggest strategies for interpretation. Principles of geographic interpretation are outlined, and the terms geointerpretation and sense of space are suggested and defined. 


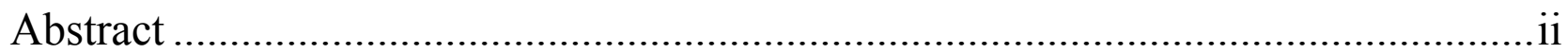

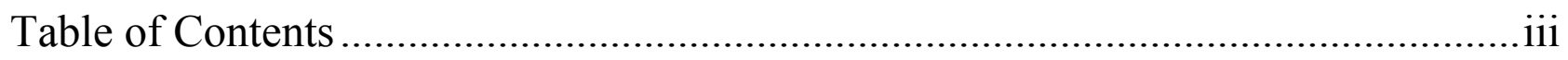

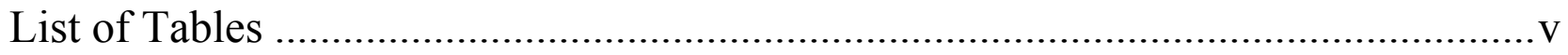

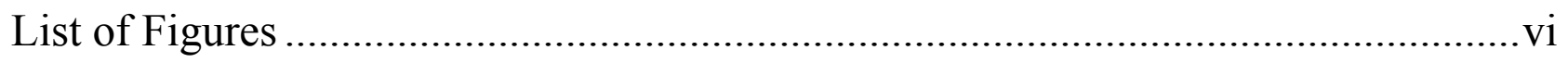

I. Wildland Fire and Interpretation .............................................................................. 1

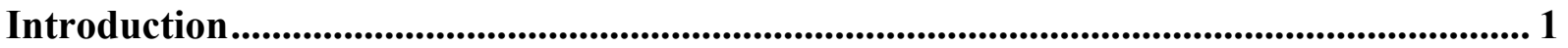

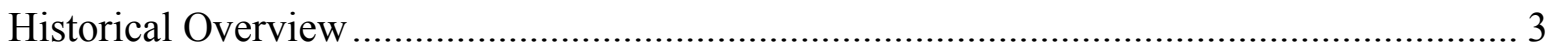

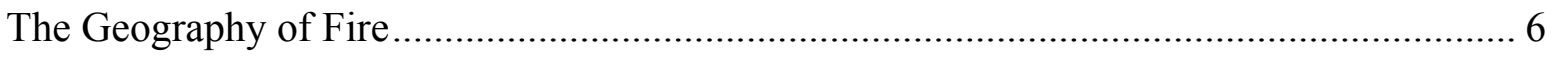

Social Science Research on Fire.............................................................................. 8

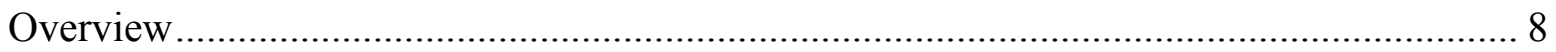

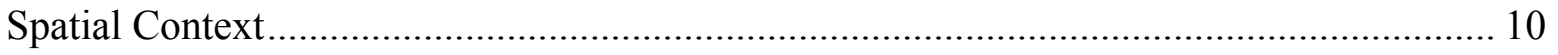

Fire and Interpretation................................................................................................................ 12

Objectives and Research Questions .......................................................................................... 15

II. A Review of Literature with Implications for Interpretation ............................................ 16

Geographic Interpretation ............................................................................................................. 16

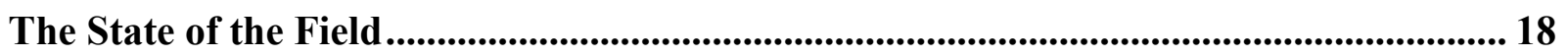

Acquiring Spatial Knowledge .......................................................................................................... 22

Spatial Cognition..................................................................................................................... 27

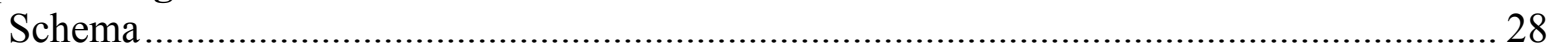

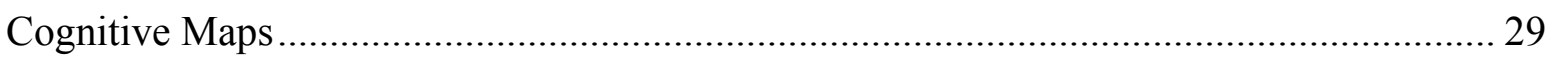

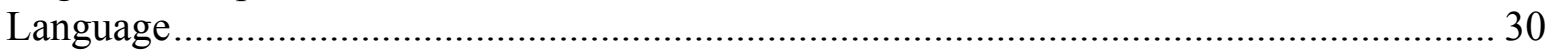

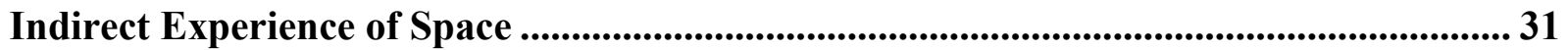

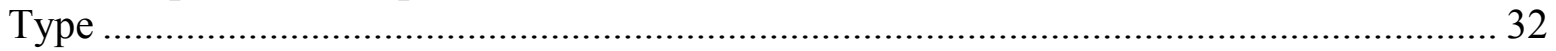

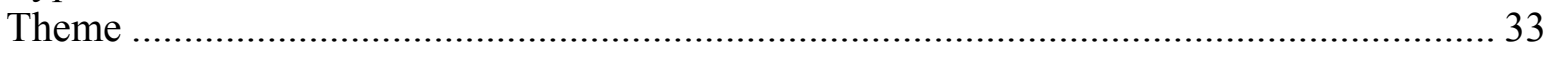

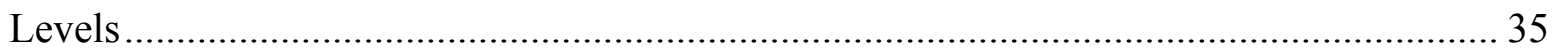

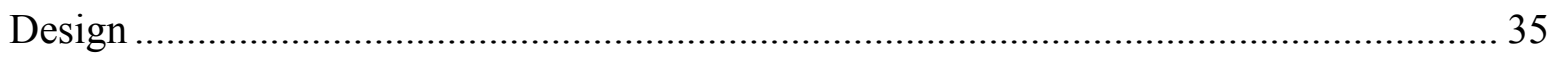

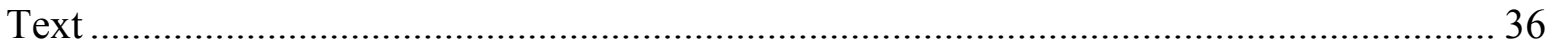

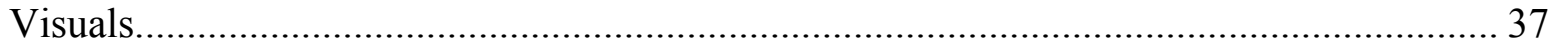

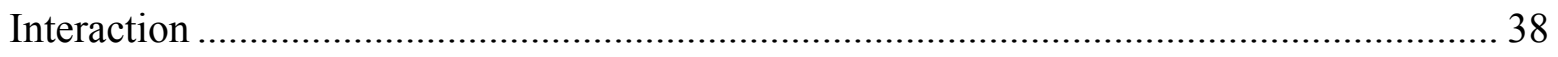

Synthesis................................................................................................................................. 43

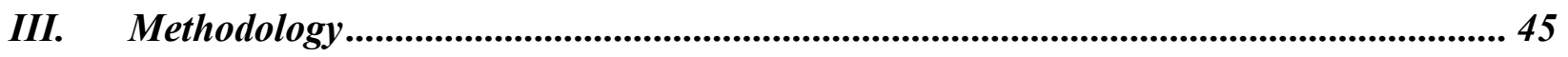

Visitor Study ....................................................................................................................................... 45 


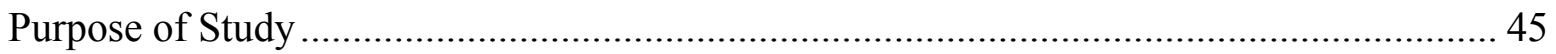

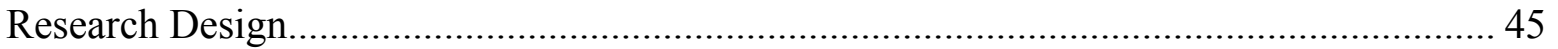

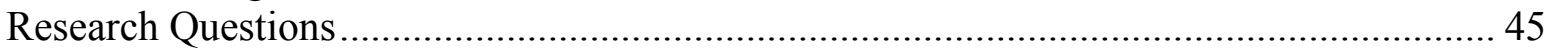

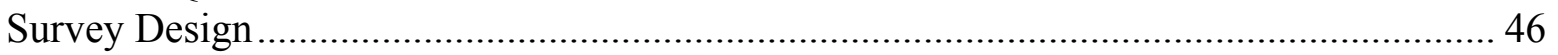

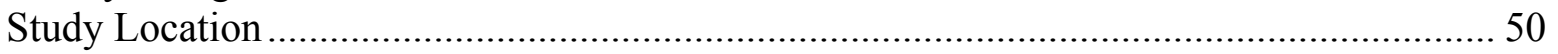

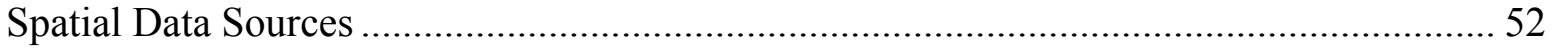

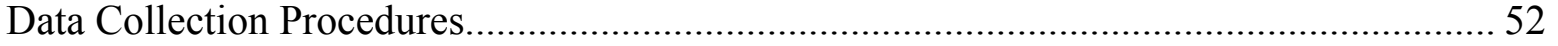

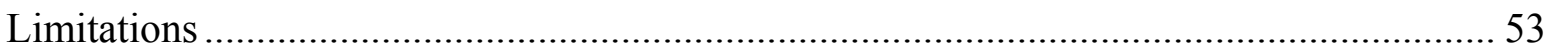

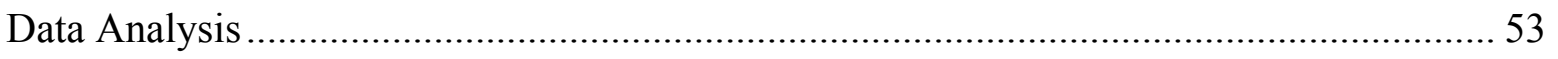

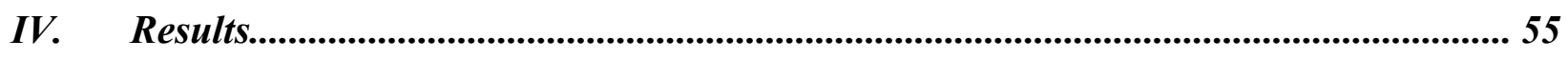

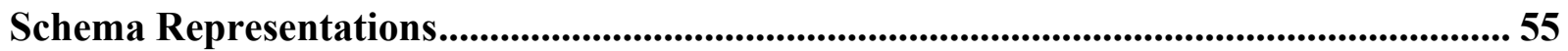

Visitor Descriptions of National Forests..................................................................... 55

Visitor Response to Questions on Structural Characteristics of National Forests ............... 58

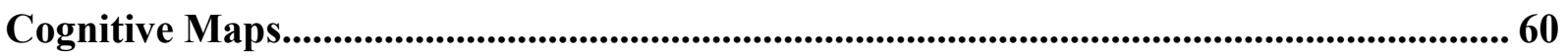

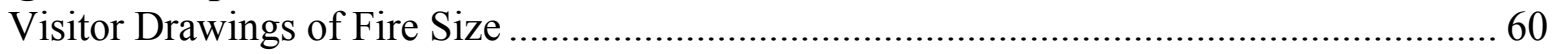

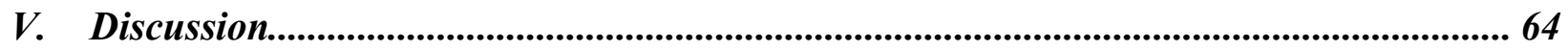

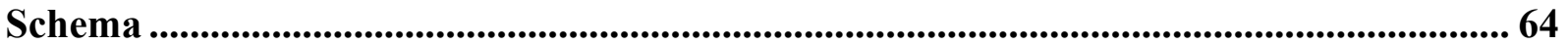

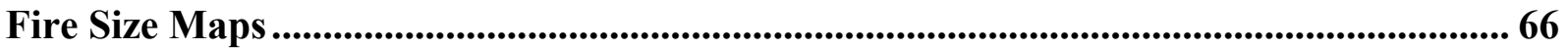

VI. Conclusions and Recommendations ............................................................................. 71

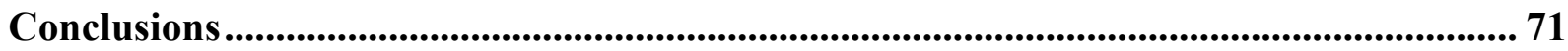

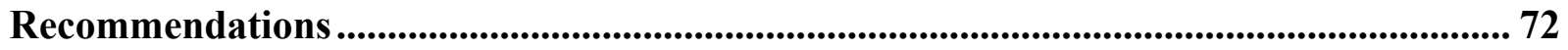

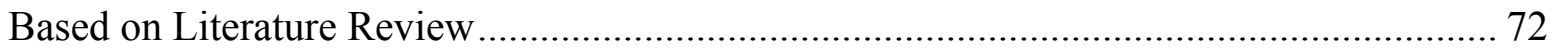

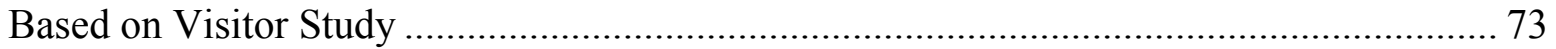

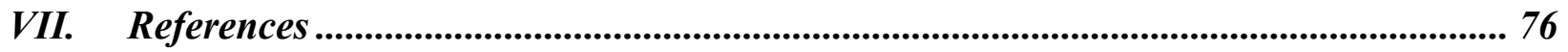

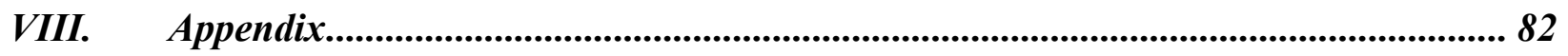

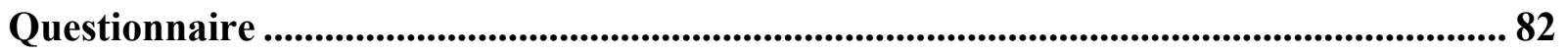




\section{List of Tables}

Table

1 Types of geographic interpretation

2 Components of spatial knowledge

$3 \quad$ Features of a National Forest

$4 \quad$ Coding framework and sample responses

$5 \quad$ Mental images of National Forests

6 Structural characteristics of National Forests

$7 \quad$ Statements describing the Herman Creek fire
Page

16

24

56

57

58

59

60 


\section{List of Figures}

Figure Page

$1 \quad$ Columbia River Gorge National Scenic Area 50

$2 \quad$ Herman Creek fire 51

3 Composite fire size drawings (females) 61

$4 \quad$ Composite fire size drawings (males) 62

$5 \quad$ Size range of fire drawings 63

$6 \quad$ Effect of language on fire size drawings 67 


\section{Wildland Fire and Interpretation}

\section{Introduction}

One of the primary roles of the twenty-first century land manager is to communicate with the public in a highly effective manner. To this end, managers often use cutting edge interpretation and outreach materials to teach people about the value of natural resources and the methods used to manage them. Communicating complex scientific concepts in an enjoyable and meaningful manner can be a challenge. For example, managers have been striving to counteract the unexpected negative effects of the Smokey Bear campaign - the public's extreme aversion to natural fire in American forests (Arno \& Allison-Bunnell, 2002). Managers teach people the ecological benefits of fire not only for the sake of education, but also to increase support for fire policy and management techniques. An increase in knowledge of ecological processes has been repeatedly linked to an increase in support for fire policy (Taylor \& Daniel, 1985; Carpenter et. al., 1986; Nielsen \& Buchanan, 1986; Loomis, Bair, \& Gonzalez-Caban, 2001). However, a limitation of this research is that it has not considered people's understanding of large-scale environments. While small-scale environments can be experienced all at once and are easily accessible to individuals, large-scale environments cannot be perceived holistically (Peuquet, 2002; Freundschuh \& Egenhofer, 1997). It may therefore be more difficult for people to form personal connections with the resource - a fundamental goal of interpretation. The goal of this thesis was to examine visitors' perceptions of large spaces and the role of spatial knowledge in the interpretation of natural resources.

Understanding people's perceptions of large-scale environments may help park managers communicate concepts that involve broad landscapes. Recreation and tourism have benefited considerably from the concept of sense of place that was adapted from the field of geography 
(Hall \& Page, 2002). Sense of place refers to the emotional attachment that people have to individual places (Cresswell, 2004). It follows that sense of space can be used to describe how people relate to larger landscapes. Research on how people learn spatial knowledge is critical to developing interpretive techniques for teaching people about large-scale environments. A review of the social science literature on wildland fire reveals an emerging need for this type of research.

Over the past 30 years, numerous studies have been conducted on the relationship between increases in knowledge of fire effects and levels of support for fire management activities. Despite the positive results, researchers have found that the public consistently misunderstands the size of wildland fires. Cortner, Zwolinski, Carpenter, and Taylor (1984) found that residents of Tucson, Arizona were not familiar with the average number of acres burned in the nearby Coronado National Forest. McCool and Stankey (1986) discovered that survey respondents were unable to correctly answer a question about the size of natural fires. Consequently, they identified a need for education materials on the subject. Taylor (1990) reiterated the public's lack of knowledge about fire size and linked beliefs concerning fire area to attitudes towards fire management. Similarly, Carpenter et. al. (1986) found that when describing their mental image of a forest fire, visitors frequently mentioned fire area. In addition, the authors found if people believed less area had burned, the more likely they were to approve of allowing fires to continue burning. They suggested that phrases such as "large area" and "immense size" have a negative effect on perceptions of forest fires. Taylor and Mutch (1986) agreed that approval is tied to beliefs that fires burn relatively small acreages and stated that incorrect assumptions about fire size persist in the absence of information to the contrary. 
These observations suggest that the spatial nature of fires needs to be communicated more effectively.

Current techniques for communicating the amount of area burned by forest fires may in fact be contributing to misconceptions about fire size. During the highly controversial fires that occurred in Yellowstone National Park in 1988, the maps provided to the media by managers created false impressions of the extent of the fires. These maps contained drawings of the outer perimeter of fire management zones that were completely shaded in black. Only some of the forest within these perimeters had actually burned, yet the media and the public assumed the black areas on the map indicated that the entire area had been blackened by fire (Reid, 1989). This demonstrates a disconnect between the information being provided by managers and the public's interpretation of its meaning. Clearly, improved communication techniques are needed to prevent these misconceptions.

\section{Historical Overview}

Wildfire is currently a challenging problem facing land managers in the western and southern regions of the United States. The issue is based in part on recent trends in population and demographics, management practices and the political climate. As a result of these trends, social scientists have dedicated considerable research efforts to studying the human dimensions of fire and land management. Since the environmental movement in the 1960s, public interest and involvement in land management planning has increased. Policies such as the National Environmental Policy Act (NEPA) of 1969 direct agencies to consider all aspects of the human environment during planning. This includes the social and cultural environment in addition to the natural environment. Macie and Hermansen (2003) considered changing public attitudes towards natural resource management as the social trend with the greatest impact on the way 
public lands are used. During the last 30 years, management of National Forests has arguably received the most attention, both in terms of timber cutting and fire policies. The contentious nature of these issues has led to extensive research on public attitudes and levels of support for management actions. Involvement of the public is essential to preventing unexpected negative reactions to management activities and policy decisions. Future management may depend in large part on perceptions of public lands and the strategies used to manage them. Thus, managers can best serve public interests by understanding the way people relate to these landscapes.

Arno and Allison-Bunnell (2002) identified distinct historical eras in the human relationship to fire in America. From ancient times to 1910, Native Americans and early settlers used fire for cultivating the land for agriculture, attracting or driving game animals, clearing land for homesteads, and creating grazing lands for cattle. In the late 1800 s, fires ignited in the slash left from logging operations and raged out-of-control, destroying many towns. Fire became a menace, and by the beginning of the twentieth century conservationists were advocating for the protection of the nation's remaining forests. Forestry developed as a profession during this time, and many early foresters believed fire suppression was necessary to preserve the forests that had not already been destroyed by logging and fire. In 1910, three million acres of land burned in just two days throughout northern Idaho and Montana. Public outcry coupled with changes in the political climate cemented the Forest Service's position on fire suppression. From 1935 1978, "manpower, equipment, and technology were marshaled in a paramilitary campaign against fire" (Arno \& Allison-Bunnell, 2002, p. 20).

In the late 1920s, federal land management agencies began to realize that despite enormous expenditures, they were losing the war on fire. In addition, they discovered that 
suppression was causing the forests to build up unnatural loads of fuel. By the late 1970s, managers were beginning to embrace the ecological benefits of fire and to allow naturally ignited fires to burn. Ironically, changes to management policies did not come easy, since the Forest Service's Smokey Bear campaign had turned public sentiment against fire, regardless of the cause of the fire. This brief history indicates that America's relationship with fire is circularunderstanding of the role of fire has come back to that of ancient times, with fire as a necessary part of nature and a tool for shaping the land (Arno \& Allison-Bunnell, 2002). Yet recent trends in demographics, management and politics are continuing to challenge America's attempts to coexist with fire.

The American population is migrating to the western and southern states in increasing numbers. Dwyer and Childs (2003) cited several reasons for this movement of people across the landscape. Modern technology is a major factor in the ability of people to move from population centers. An increasing number of people are able to study and work from home with the proliferation of web-based services, telecommunications, and transportation options. Employers can reduce costs by allowing employees to work from home, in turn providing workers greater flexibility in choosing where they live. The opportunity for desirable housing has increased in rural areas, and people are opting to move closer to places that afford recreation opportunities. In addition, the 'baby boom' generation is retiring, and many have the means to build new homes or move into seasonal or second homes. As a result of these population and demographic trends, ever-increasing numbers of homes appear in the Wildland-Urban Interface (WUI). The presence of humans in the fringes of forest landscapes and other ecosystems is creating a challenge for land managers. Natural processes such as fire do not recognize the artificial boundaries of land ownership. Furthermore, as people migrate, they "may transfer ideas and practices from one 
landscape to another" (Dwyer \& Childs, 2003, p. 156). People without a historical relationship with the land may not understand the role of natural processes and management techniques. New residents can redirect land-use goals, which can have a significant effect on resource management (Dwyer \& Childs, 2003). Managers are not just faced with more people, but also with people that may value the land in fundamentally different ways.

Recent trends in fire management practices have shifted from complete suppression to a threefold approach of setting prescribed fires, allowing natural fires to burn, and suppressing fires near human settlement. A century of fire suppression has left National Forests with unnatural levels of fuels: needles, branches, and thickets of understory trees. The most cost effective method for reducing these fuels is prescribed fire, which burns at a low intensity across the forest floor, leaving the mature trees intact. Winter and Fried (2000) discussed homeowner perspectives on the use of fire as a management tool. They found that the use of prescribed fire often has a negative influence on the attitude of local residents. The authors attribute this to the lack of media attention on the numerous successful uses of prescribed fire, focusing instead on the occasional escape of prescribed fires and resulting property damage. As this management trend continues, there will undoubtedly be more conflicts with people living on the fringes of public lands. Communication is key to minimizing these conflicts.

\section{The Geography of Fire}

Recent shifts in ecological theory have resulted in a fundamental change in the concept of space (Perry, 2002). People traditionally viewed landscapes as homogeneous, both in terms of composition and processes. Fire suppression policies were based on the idea that landscapes should be homogeneous and kept in a state of equilibrium. Ecologists have more recently embraced the ideas of non-equilibrium and landscape heterogeneity (Perry, 2002). These 
shifting viewpoints stemmed from changes in ecological theory, such as the balance of nature concept. Under this paradigm, scientists believed natural systems were static and disturbance of any kind was destructive. Ecologists have now rejected this idea in favor of a non-equilibrium premise, with disturbance playing a significant role (Perry, 2002). In the United States, this shift is evident in the management of natural resources. At the turn of the twentieth century, numerous reserves and parks were created to protect the nation's remaining forests. Managers believed fire suppression was necessary until the late 1970s, when they realized that fire was essential to forest renewal and that land should not be preserved in a state of constant equilibrium (Arno \& Allison-Bunnell, 2002).

Disturbance plays an important role in defining the geography of an area. For instance, fire can create mosaic landscapes that resemble patchwork quilts. These patches create edge effects, providing habitat for many forms of wildlife and meadows that are aesthetically pleasing to humans. In addition, these forest mosaics can control the spread of future disturbances, such as wildland fire. Removal of a disturbance can also profoundly affect the geography of an area. For instance, the landscape-replacing fires of recent years have likely resulted from human attempts to keep the forests homogeneous. Ecological processes are not stable and spatial patterns in nature are highly dynamic (Perry, 2002). An understanding of the geography of fire has contributed to a more holistic ecosystem management philosophy. This knowledge has encouraged managers to extend the scope of their responsibility across administrative boundaries and to involve multiple stakeholders (Cheng \& Daniels, 2003). However, these ecological and spatial concepts may not be understood by all stakeholders, and should therefore be cultivated in the minds of the public. 
Social Science Research on Fire

$\underline{\text { Overview }}$

At the heart of any communication strategy regarding natural resources is a mechanism for allowing managers to educate themselves about the public (Taylor \& Mutch, 1986). This involves studying people's perceptions of the land and responses to the effects of land management practices. One method traditionally used by researchers is to test people's responses to the visual qualities of the land. For instance, Taylor and Daniel (1985) and Scott (1998) used sets of photographs to represent the effects of a variety of land management practices (thinning, prescribed fire, no action). Visitors indicated their preferences by selecting the photo they found to be visually pleasing. Results suggested that visitors preferred stands that have been treated by light thinning or light fire versus untreated stands. Such treatments ultimately affect the spatial distribution of the trees and vegetation, which has been linked to scenic quality (Vaux, Gardner, \& Mills, 1984). This method is qualitative in nature and may not produce sufficient information for researchers and managers to justify decisions. Shindler, Brunson, and Stankey (2002) cautioned against using scenic quality as the entire basis for determining levels of public support. They argued that from "a social science standpoint, this approach seems limiting, largely because other contextual factors are not accounted for in these assessments" (p. 36). Visual quality tests were an early attempt by managers to gain an understanding of public perceptions of the land.

More recently, other methods have been used to study public perceptions of land management practices. For instance, economic tests allow people's preferences to be expressed in a more quantitative manner that may be easier for researchers to interpret. Englin, Loomis, 
and Gonzalez-Caban (2001) used travel-cost models to determine the response of recreational users to the effects of fire. The premise of this technique is that price - which includes travel cost and travel time - determines whether or not a person will visit a site. Since photographs are also used for this method, the results still reflect visitor response to the physical characteristics of the forest. Another method that combines the visual quality test with an economic test is the “willingness-to-pay" model (Vaux et. al., 1984). This technique allows the visitor to indicate the fee they are willing to pay based on the scenic quality of an area. Photographs are again used to represent the structural characteristics of the forest. The question remains - which characteristics are influencing people's response?

The public may react negatively to management practices if the condition of the landscape does not meet their expectations. Measuring public reactions accurately can be difficult for managers. To meet this challenge, theories have evolved over time from traditional scenic quality and economic paradigms to more complex approaches. These include the normative theory and the concepts of social acceptability and social trust. The normative approach has been used to determine the public's tolerance for conditions encountered on public lands (Kneeshaw, Vaske, Bright, \& Absher, 2004). Norms are the beliefs people share as a result of familial or societal influences. This system allows managers to monitor certain variables - known as indicators - for adverse changes. For example, excessive human use can lead to loss of vegetation. The point at which this condition becomes unacceptable is used to define the minimum standard that must be maintained (Manning, 2000). The norm theory calls for management based on the expectations of the public, which may differ from the judgment of managers. This approach provides an opportunity for these disparate views to be aligned by altering management practices or educating the public. 
The concepts of social acceptability and social trust evolved from recent public involvement initiatives. Shindler et. al. (2002) relied on the following definition of social acceptability as originally developed by Brunson in 1996:

a condition that results from a judgmental process by which individuals (1) compare the perceived reality with its known alternatives; and (2) decide whether the "real" condition is superior, or sufficiently similar, to the most favorable alternative condition... (p. 4).

The acceptability of management practices on public lands is often directly related to the amount of trust the public holds for the land management agency. Social trust is defined by Winter, Vogt, and McCaffrey (2004) as "the willingness to rely on those who have the responsibility for decisions and actions related to risk management" (p. 9). People are more accepting of management practices if they trust the agency performing them. Thus, the goal of the manager is to create opportunities for building trust.

The increasing emphasis on active public involvement indicates that research in this field has evolved significantly over the past 30 years. The methods used in early research asked the public to simply indicate their preferences for scenic quality. This is largely superficial compared with the modern techniques of actively seeking to gain acceptance and build trust. This approach goes beyond simply gauging people's reactions, and is the key to an adaptive management strategy that evolves in response to the changing needs and perceptions of the public.

\section{$\underline{\text { Spatial Context }}$}

One of the concepts reiterated throughout the literature on public perception is that social acceptability varies by location. The most recent research in this area has focused on the need to consider situational influences. Kneeshaw et. al. (2004) argued that "the different situational factors that define a given context influence standards for what is acceptable" (p. 478). These 
variables include socio-economics, patterns of land ownership, rural development, demographics, transient populations (owners of second homes, tourists), and many other factors. Natural areas are located in multiple states, near a variety of communities, and within lands managed for different uses. Thus, a one-size-fits-all prescription would not be appropriate. Shindler et. al. (2002) advocated taking spatial context into consideration during planning. Managing ecosystems and watersheds at the landscape-level by returning disturbances can be controversial. Spatial context is important, because "practices and conditions acceptable in one situation will not necessarily be acceptable in another" (Shindler et. al., 2002, p. 20). Regional differences in perceptions of land use should play a role in determining the management practices suitable for a particular location (Jacobson, Monroe, \& Marynowski, 2001).

In addition to regional differences, the effects of changing scales must be taken into account by natural resource managers. Cheng and Daniels (2003) asserted that managers cannot take scale for granted when dealing with the public, because stakeholder support may be affected by the physical size of a setting. Members of the public rely on personal experience with smaller places and may therefore miss broader issues and concerns. The meanings of places at scales larger than the community level tend to become abstract and highly generalized (Galliano \& Loeffler, 1999). This is supported by Shindler et. al. (2002), who suggested that social acceptability of management practices is influenced by differing scales. They made the following observations: 1) people identify with places versus large landscapes, 2) people have a difficult time evaluating conditions at the landscape level because it is not a familiar frame of reference, and 3) people are not conditioned to recognize that forest patterns exist at different scales. In regards to the third observation, park visitors may not understand that fire creates a finely grained mosaic of small patches in some ecosystems and a series of large patches in others 
(Billing, 1993). Thus, the effect of scale is an extremely important issue in public land management.

The problem of spatial context is also an issue for property owners in the Wildland-Urban Interface. Winter and Fried (2000) found that homeowners approved of landscape modification on a conceptual level, but they equated landscapes to public lands. Many did not believe that modification of vegetation should be done on private property. Dwyer and Childs (2003) concluded that people are accustomed to addressing issues on a site-by-site basis rather than by looking at linkages across the landscape. They stated that WUI residents need help visualizing their property as a resource that must be managed in order to contribute to landscape-level objectives. This is difficult for managers to accomplish considering the general lack of knowledge about the spatial characteristics of landscape-level processes. The increasing number of people living in close proximity to public lands has led managers to bring educational messages directly to local communities. Private owners have essentially become land managers and the Forest Service is using natural resource consultants to assist private landowners in developing stewardship plans (U.S. Forest Service, 2001). Thus, public agencies are able to work in collaboration with private owners to manage the landscape as a whole. Natural resource interpretation is an important component of the communication process that occurs between land managers and the public.

\section{Fire and Interpretation}

The National Association of Interpretation defines interpretation as "a communication process that forges emotional and intellectual connections between the interests of the audience and the inherent meanings in the resource" (Basman, 2003, p. ix). As established previously, an increase in knowledge of ecological processes has been repeatedly linked to an increase in levels 
of policy support (Taylor \& Daniel, 1985; Carpenter et. al., 1986; Nielsen \& Buchanan, 1986; Loomis et. al., 2001). Researchers who study fire and interpretation have made several important recommendations for increasing the effectiveness of these programs.

Fire information programs should provide definitions of fire management terms, comparisons of wild and prescribed fire, illustrations of fire behavior, and descriptions of fire effects and benefits (Loomis et. al., 2001). The content of these programs needs to be directed toward a broad cross-section of adults and should address specific situational factors - such as fire size (Carpenter et. al., 1986). For instance, fire programs should include information about the average size of natural fires and the capability of fires to create important forest openings (McCool \& Stankey, 1986). One option that has been proposed is to use Smokey Bear's fame to reeducate the public on the role of wildfire and fire management policies (Manfredo, 1990). Some researchers have advocated targeting specific population groups in fire information programs. Although these studies are dated, Cortner et. al. (1984) and Gardner (1985) found that women may be more risk adverse than men and less likely to tolerate fire-induced changes in forests. In these studies, women scored lower on knowledge questions pertaining to the beneficial effects of fire.

In addition to the content of fire information programs, the presentation method is also an important consideration. The most effective educational programs are those that emphasize twoway communication between managers and members of the public (Shindler et. al., 2002). Some researchers have suggested that passive communication devices such as brochures, posters, and audio-visual programs are more effective when followed by some type of interaction with agency personnel (Toman, Shindler, \& Reed, 2004). Other researchers have found virtually equal results from interpreter-guided and audio-visual programs (Nielsen \& Buchanan, 1986). 
Similarly, information brochures have been shown to produce significant changes in knowledge and attitudes regarding fire. But the design of these brochures is important - they must be carefully crafted to prevent information overload among readers (Taylor \& Daniel, 1985).

An education technique that is gaining popularity is field visits to sites treated with prescribed fire. These visits provide an opportunity for the public to see the effects of management practices first-hand. This method has the additional benefit of allowing the manager to observe reactions and discuss issues that are pertinent to the visitor (Toman et. al., 2004). These issues are important in the development of interpretive materials, since each message should be geared towards the personal experiences of visitors (Ham, 1992). In addition, managers must be cautious not to exaggerate the benefits of management actions in the way the Smokey Bear campaign exaggerated the negative effects of fire (Jacobson et. al., 2001). Ideally, education should be a continuous activity, as people's fundamental belief systems take time to change. Taylor and Daniel (1985) found that despite an increase in knowledge and verbally expressed support, people's perceptions of the effects of fire on scenic beauty and recreational acceptability remained unchanged. Interpretation can play a major role in building public support, and a variety of tools and techniques for communicating complex subjects to the public can aid in this process (Stankey, 1976).

Communicating the locations of places and the relationships between places is important for agencies charged with managing landscapes that cover vast areas and cross numerous boundaries. Involving the public in land management practices - such as forest stewardship requires people to understand spatial relationships. Geographers look for ways to effectively communicate spatial information by studying people's mental representations of space (Freundschuh \& Egenhofer, 1997). The spatial cognition literature is rich in information about 
the nature of spatial learning. Integrating this wealth of knowledge with the principles of interpretation may allow resource managers to further increase understanding and levels of support for management activities. Owing to the recent move towards landscape level management, geographic interpretation may hold the key to these goals.

\section{Objectives and Research Questions}

In order to examine the role of spatial knowledge in the interpretation of natural resources, two major objectives were defined for this thesis. The first objective was to synthesize the literature on spatial cognition from the fields of geography, environmental psychology and education and to consider implications for interpretation. A second objective was to study visitors' mental images of National Forests and perceptions of fire size. These visitors were asked questions about their cognitive representations of forest environments and their perceptions of the size of a recent fire. Three methods were adopted from the research on human spatial cognition: spatial schema representations, cognitive mapping, and language structure. Questions addressed in this thesis include: How is spatial knowledge acquired? How can interpretation be used to effectively communicate geographic information? What are visitors' mental representations of National Forest environments? Do visitors understand descriptions of fire size? Do male and female visitors have different perceptions of fire size? Does the language used to describe fire affect perceptions of fire size? 


\section{A Review of Literature with Implications for Interpretation}

\section{Geographic Interpretation}

Interpretation has several subfields, including - but not limited to - historical, cultural, and environmental interpretation. Many others exist, even if they haven't been formally labeled and researched by interpretive professionals and academics. This paper proposes the recognition and development of Geographic Interpretation as another important subfield. Nearly every visitor center, interpretive center, discovery center or even kiosk provides geographic information in some form - usually a map. Many facilities interpret the geography of a park or historical site using more sophisticated methods (See Table 1). However, these are often just used to interpret geology. Thus, these tools may not be used to their full potential due to a lack of knowledge in the interpretive profession about the way geographic information is learned.

\begin{tabular}{|l|l|}
\hline \multicolumn{1}{|c|}{ Types of Geographic Interpretation } & Gross \& Zimmerman (2002) \\
\hline 3-dimensional wall map emphasizing routes & p. 61 \\
\hline Room-size relief map & p. 9,69 \\
\hline Computer touch screen map & p. 87,187 \\
\hline Tile floor map & p. 89,142 \\
\hline Sign-mounted tactile map oriented to landscape & p. 94 \\
\hline Free-standing table-top topographic map & p. 99,205 \\
\hline Interactive relief model with features visible through windows & p. 151 \\
\hline 3-D model with oblique view map & p. 153,181 \\
\hline Open diorama & p. 174,186 \\
\hline GIS overlay projected onto topographic model & p. 186 \\
\hline Children's table-top map & p. 192 \\
\hline $\begin{array}{l}\text { Interactive relief model with information organized according } \\
\text { to length of stay }\end{array}$ & p. 196 \\
\hline Orientation \& wayfinding maps (indoor \& outdoor panels) & p. $87,148,208-209,215$ \\
\hline Living map programs & N/A \\
\hline Video or computer animation & N/A \\
\hline Satellite or photographic imagery & N/A \\
\hline Laser/light shows emphasizing map features & N/A \\
\hline
\end{tabular}

Table 1: Types of geographic interpretation used in visitor centers. See Gross \& Zimmerman (2002) for examples. 
The field of natural resource management long ago adopted the concept of sense of place - an idea whose roots can be found in the field of geography (Hall \& Page, 2002). The goal of resource interpretation has been to connect visitors to the meaning and spirit of these places. Yet interpretive sites are more than just a collection of natural formations, historic buildings or ancient ruins. These objects and places interrelate spatially, giving the overall landscape a meaning of its very own. People relate to these large spaces in a fundamentally different way than they relate to individual places (Peuquet, 2002). Thus, the hope is that geographic interpretation can be used to connect visitors to the landscape as a whole by helping them to develop a sense of space.

Once confined to the academic and professional communities, geographic information systems are becoming increasingly accessible to the public. For instance, newspaper stories discussing the use of Google Earth to view aerial photographs of the damage from Hurricane Katrina brought the field to the attention of the public in a very dramatic way (Spice, 2005). As tools like Google Earth and Global Positioning Systems (GPS) become more prolific, the field of interpretation has an opportunity to use this newfound interest in geography as a tool in interpretive displays and programs. Thus, recognizing geographic interpretation as a growing subfield and embracing the possibilities it offers will prove timely.

The trend in the world of geography is to shorten the word geographic to geo and combine it with other words to create new terms. Words like geocaching, geoinformation, geodatabase, and geoprocessing are used to emphasize geographic or spatial ways of thinking about subject matter (Longley, Goodchild, Maguire, \& Rhind, 2005). In a more interpretive context, Kitchin (1997) described a tour of a city and the surrounding area as a geohistoric tour. 
Similarly, National Geographic (2006) coined the word geotourism, defining it as sustainable tourism that enhances the geographical character of a place. It therefore follows that the subfield of geographic interpretation proposed here should be known as Geointerpretation.

Why is Geointerpretation important? Resource managers are increasingly asking the public to understand more abstract spatial concepts such as fire regimes, habitat corridors, historical landscapes, cultural regions and watersheds. Yet, lacking detailed understanding of visitors' spatial knowledge, many sites do not currently accommodate or facilitate visitors' spatial learning processes. This paper draws upon findings from research in spatial cognition - a subject that has received significant attention from the fields of geography, environmental psychology and education - to make recommendations for interpretation. The following research questions are addressed: How is spatial knowledge acquired? How can interpretation be used to effectively communicate geographic information?

\section{The State of the Field}

Geointerpretation has received limited attention from academic and professional researchers. However, a few have recognized the importance of including spatial information in interpretive programming and displays. The subject was addressed by Knopf (1981), who studied the role of spatial information in visitors' understanding of the historical events that took place at Gettysburg National Park. The author found that first-time visitors who participated in both the Electric Map and Cyclorama programs in addition to a driving tour of the park reported significantly higher levels of perceived clarity regarding the historical events that occurred at Gettysburg. The Electric Map program combines a room-sized three-dimensional representation

of the battleground with audio narratives and light displays. The Cyclorama program takes place in a building with a 360-degree painting of the Gettysburg landscape and uses narration and 
lighting effects to emphasize natural landforms, battle events and cause-effect relationships. Knopf (1981) considered the order of visitation and found significantly higher levels of perceived clarity in visitation patterns that began with the Electric Map and included both the driving tour and the Cyclorama. In other words, those visitors who were oriented to the site first and participated in two additional spatial experiences reported a significantly higher level of understanding concerning historical events. A limitation of this study is that the results were based on self-reported perceptions of clarity without the use of pre- and post-tests. Although all of the respondents were first-time visitors, clarity may have been based on other variables. The author recognized these limitations and called for future studies on the chain of interpretive experiences and the effectiveness of spatial orientation programs. To date this challenge has gone largely unanswered.

Spatial learning of first-time visitors has long been an area of study for tourism researchers; however, these studies have been primarily focused on urban environments. A study by Young (1999) aimed to extend this knowledge to include tourists' spatial awareness of large-scale natural environments. Visitors to Australia's Daintree National Park were asked to draw sketch-maps of a specific area within the park. The results indicated that visitors experienced difficulty in conceiving of the area spatially. Many visitors drew non-spatial representations, relying instead on symbolic impressions of the area. The representations that were drawn spatially were low in quality or drawn at an inappropriate scale. The author concluded that many of the visitors possessed almost no spatial context within which to frame their experience. Many visitors' conception of the area was retained as a vague impression, rather than in a distinct spatial form. The author suggested that tourists have less motivation to acquire spatial knowledge due to the short duration of their stay. Interpretation may be able to 
bridge this gap, but Young (1999) asserted that the role of spatial knowledge in place interpretation remains unknown. The author recommended further research on the subject to aid in the production of meaningful maps and the interpretation of natural environments.

Advances in computerized geographic information led to a flurry of articles on the potential of remote sensing, Geographic Information Systems (GIS), and Global Positioning Systems (GPS) to enhance interpretive experiences. For example, Vander Stoep (1990) recommended using remote sensing (aerial photographs and satellite images) to provide visitors with a new perspective of the landscape. These tools allow visitors to see patterns on the surface of the earth that are only visible from above. The author believed these views from above could be used to challenge visitors to analyze and interpret visual information themselves. Evans, Butcher, Dufficy, and Hamel (1999) reiterated the importance of providing visitors with a bird's eye view of landscapes. The authors advocated using aerial photographs and satellite images to reveal patterns of land use and to demonstrate changes in the landscape. In addition, these tools can be used to interpret the effects of scale and to provide global connections to local issues.

In addition to remote sensing, Clebsch and Curwen (2000) identified Geographic Information Systems (GIS) as a tool for connecting meanings and ideas to places. Maps created in a GIS can communicate these meanings and help visitors form emotional and intellectual connections to a resource. Similarly, Kerski and Reiter (2004) recommended using Global Positioning Systems (GPS) and US Geological Survey (USGS) resources to interpret the landscape. The authors suggested incorporating these tools into interpretive programming in order to extend knowledge about the earth and human/environmental issues. While the use of computerized geographic information was once cost prohibitive, recent advances in web-based technology have made these tools increasingly accessible. 
Non-computerized geographic interpretation has also received some attention from interpretive professionals. Living maps were introduced by Bremen, Albrecht, Dale, and Hertel (1992) as a tool for providing visitors with a solid geographical foundation. The authors suggested that this foundation would bridge the gaps in a visitor's understanding of a site. Living maps are room-size maps that allow visitors to add props and manipulate the layout of the features. These maps may be built into the floor, painted on canvas, or woven into rugs or carpets. They facilitate discussions of complex issues by allowing participants to become part of the space represented by the map and to interact with the map's features. The living map program was initially developed in response to a visitor's complaint that brochure maps are too small, making it difficult to visualize resources and their relationship to one another. Similarly, Spear (1997) endorsed living maps as a tool for allowing visitors to create maps themselves and to actively explore within these maps. The popularity of living maps has spread, but they have been used primarily for children's programming. The potential for adapting living maps to teach geographic concepts to adults has yet to be explored.

Finally, the topics of orientation and wayfinding have received some consideration in the interpretation literature. Gross and Zimmerman (2002) discussed the need to account for visitors' spatial orientation and wayfinding needs. The authors stressed the importance of these tools in comforting people in unfamiliar surroundings. The most common tools used to meet the spatial orientation and wayfinding needs of visitors are maps and signs. While a comprehensive guide to geographic interpretation does not exist, Gross and Zimmerman's (2002) guidebook to interpretive centers includes numerous examples of geographic interpretation (See Table 1). In addition, Kealy (1998) discussed the use of wayfinding maps as an interpretive tool. The author focused on using cartographic principles to create interpretive maps designed to convey a theme. 
Kealy (1998) suggested that interpretive maps can communicate meaning by including only those features that are related, versus a reference map that merely shows the location of objects and places that may be unrelated and irrelevant to the visitor.

This literature review clearly demonstrates the pertinence of geographic interpretation. It also identifies a lack of research on the role of the various tools and techniques in contributing to the spatial learning of visitors. Further research will allow geographic interpretation to progress with the support of empirical study. The following sections will examine and synthesize the literature on spatial cognition from other disciplines and consider their contribution to the theory and practice of geographic interpretation.

\section{Acquiring Spatial Knowledge}

Space exists at a variety of different scales - the area between molecules in a droplet of water is a type of space, as is the area between houses in a neighborhood. Space exists within the boundaries of a national park, between the earth and the sky, and across the solar system. Peuquet (2002) summarized the basic elements of spatial knowledge. First, humans have the unique capacity to conceive of spaces at scales beyond that which can be perceived directly. People can visualize processes that occur at microscopic, global or astronomical scales without ever experiencing the phenomenon personally. Secondly, this ability is developmental, improving over time as knowledge of spatial processes grows. Third, every person, place or object interacts spatially with its environment. Homes are next to one another, rivers flow between mountains, a park is north of the city. The interaction of things across space can create a meaning very different from the meanings of the individual elements. For instance, the interactions between a river, tributary streams, trees, and a snow-capped peak create a watershed. Spatial knowledge is therefore the cumulative understanding of the meanings of space at a 
variety of scales. Since this is an aptitude that is learned, it is therefore an aptitude that can be taught (Lajoie, 2003).

Spatial knowledge is generally considered to have three main components related to locations, routes, and areas. The first component is referred to by Golledge and Stimson (1997) as declarative knowledge. This relates to a person's ability to describe what a specific location is, along with its associated meaning or significance. The second component is procedural knowledge, which enables a person to determine how far and in which direction to travel to move between significant locations. These initial routes form a network, or base map, within a person's mind. The final component is referred to as configurational knowledge. At this stage, a person comprehends an area as a whole, having filled in the gaps between the locations and routes learned previously. This level of knowledge implies an understanding of the overall layout or configuration of an area. As an example, a person learning to navigate a new city will typically begin by identifying a few significant landmarks - such as home, work, and school. The newcomer then learns which streets will permit travel between these locations. Over time, the newcomer will explore the surrounding areas and learn the overall layout of the city. This level of comprehension allows a person to devise shortcuts and new routes based on an understanding of spatial relationships (Peuquet, 2002). Theories concerning spatial knowledge are based on this idea of declarative, procedural and configurational levels of knowledge.

Researchers have variously defined these three components as landmark $\rightarrow$ route $\rightarrow$ survey, location $\rightarrow$ path $\rightarrow$ area, and place recognition $\rightarrow$ wayfinding $\rightarrow$ layout comprehension (See Table 2). Three main theories have developed concerning how people gain knowledge at each of these levels. First, Shemyakin (1962) introduced the idea that individuals develop survey knowledge by progressing consecutively through the three stages of recognizing landmarks, 
defining routes, and understanding the relational characteristics of areas. A variation of this concept is the anchorpoint theory developed by Golledge and Spector (1978), which suggests a hierarchical ordering of locations, paths and areas. This theory posits that individuals identify a few highly recognizable or often-used places as anchorpoints. People then learn paths outward from the anchorpoints, building a rudimentary network on which further spatial learning is based. As interactions occur along these paths, a spread effect occurs, allowing individuals to conceive of the area as a whole. Finally, research on wayfinding behavior focuses on place recognition, wayfinding and layout comprehension. Wayfinding is the process of planning out a route and traveling along a path to get from one location to another. Individuals must first have knowledge of the origin, destination and certain intermediate points before learning a route. Integration of these routes eventually leads to layout comprehension. Research on wayfinding behavior indicates that knowledge of the way places and routes are inter-linked emerges over multiple trials (Golledge, 1992). The important implication of these theories is that spatial learning requires multiple experiences and must progress sequentially from the declarative to the procedural to the configurational stage.

\begin{tabular}{|c|c|c|c|c|c|}
\hline \multicolumn{4}{|c|}{ Theories of Spatial Knowledge Acquisition } & \multicolumn{2}{c|}{$\begin{array}{c}\text { Types of Map } \\
\text { Information }\end{array}$} \\
\hline $\begin{array}{c}\text { Golledge \& Stimson } \\
(1997)\end{array}$ & $\begin{array}{c}\text { Shemyakin } \\
(1962)\end{array}$ & $\begin{array}{c}\text { Golledge \& Spector } \\
(1978)\end{array}$ & $\begin{array}{c}\text { Golledge } \\
(1992)\end{array}$ & $\begin{array}{c}\text { Chou } \\
(1997)\end{array}$ & $\begin{array}{c}\text { Bertin } \\
(1981)\end{array}$ \\
\hline Declarative & Landmark & Location & Place Recognition & Point & Elementary \\
\hline Procedural & Route & Path & Wayfinding & Line & Intermediate \\
\hline Configurational & Survey & Area & $\begin{array}{c}\text { Layout } \\
\text { Comprehension }\end{array}$ & Polygon & Overall \\
\hline
\end{tabular}

Table 2: Spatial learning and map design are based on three levels of knowledge/information. 
In most interpretive environments, visitors are only offered a single opportunity to experience spatial information. They are given a map and must then rely on direct interaction with the environment for additional experiences. Yet the study by Young (1999) presented earlier indicated that even after spending time in the park, tourists possessed almost no spatial context within which to frame their visit. Direct experiences alone may be insufficient to learn spatial concepts in the relatively short time most visitors spend in natural or historical areas. Guy, Curtis and Crotts (1990) studied environmental learning of first-time travelers and found that visitors need to initially form a map in their minds to improve learning from other sources. The authors further established that environmental learning can occur rapidly - an encouraging finding for the field of interpretation. Indirect methods of communicating spatial concepts are necessary if visitors are to achieve a higher level of spatial knowledge during a short visit. The key is discerning the right mix of experiences to facilitate this learning process.

The literature on spatial knowledge acquisition provides a natural starting point for designing geographic interpretation. Peuquet (2002) stressed that with progressive types of knowledge, the progression is essential to the learning process. Individuals begin by observing and selecting certain environmental features, integrating these features, and then assigning a more abstract meaning to the whole. For example, a person might identify a few restaurants downtown, group them into a restaurant district, and then identify the district as an area for social relaxation. In natural environments, such abstract meanings occur at various scales and may not be apparent to the casual observer. The goal of geographic interpretation is therefore to connect people to these more abstract meanings of space. This involves helping people progress step-bystep through the spatial learning process. 
Researchers have experimented with methods for guiding people through the process of spatial knowledge acquisition. For instance, Herman, Herman, and Chatman (1983) used a mix of experiences to help visually impaired persons learn layouts. They used a series of models and free movement to teach people the layout of an area. First, miniature representations of the objects used as landmarks allowed the participants to determine what the objects were in terms of shape. Secondly, a model showing the configuration of these objects allowed comprehension of distance and direction relationships. The third experience took place in a gym, where participants learned the effects of scale by walking between the objects. In this example, three distinct experiences allowed the participants to progress sequentially through the three components of spatial knowledge.

Is three the magic number? Returning to the study by Knopf (1981) discussed earlier, an interesting observation can be made. The author found that visitors participating in three spatial experiences (Electric Map, Cyclorama, and Auto Tour) reported significantly higher levels of perceived clarity concerning the historical events at Gettysburg. The order of visitation was important - these visitors experienced the Electric Map prior to the other two experiences. This supports the idea that the sequence of spatial learning is important and that multiple experiences are required to progress through this process. Similarly, when Thorndyke and Stasz (1980) taught people techniques for learning spatial information from maps, they found that the advantage of this training did not emerge until the third trial. Living map programs offer an illustration of how this progression can be incorporated into interpretive programming. In one example, visitors actively participated in building a map - placing placards with the names of landmarks on the map, drawing boundaries and paths with yarn, and then using props to represent distributions of animals and Native American tribes (Bremen et.al., 1992). Visitors 
built the map sequentially, allowing them to experience the map in different ways. The key is to have each experience focus on a different type of map information (landmarks, routes, or spatial relationships). Further study is required to verify the efficacy of this technique.

Maps are commonly used to communicate spatial concepts because they are designed to provide information on all three components of spatial knowledge (see Table 2). A map is composed of points, lines and areas (or polygons). A point is a feature that specifies the location of a landmark; line features represent distance and direction; and polygon features represent the boundaries of areas (Chou, 1997). In addition, maps contain three distinct levels of information: elementary, intermediate and overall information. The elementary level pertains to basic information such as the physical location of places. Intermediate information allows mapreaders to recognize networks and spatial patterns. The overall information level is a more abstract understanding, where viewers can predict interactions based on patterns and distributions (Bertin, 1981). For example, at an elementary level, maps may pinpoint the locations of fire-scarred trees; at an intermediate level, the trees form a pattern that indicates historic fire activity; and at an overall level, the existence of a fire regime can be identified.

Educating interpreters about how information is presented in a map and how spatial knowledge is learned may go a long way in helping them communicate complex spatial concepts. An understanding of how spatial information is stored in human memory will reinforce these ideas. Thus, the topic of spatial cognition will be explored in the next section.

\section{Spatial Cognition}

Spatial cognition is defined as the "mental structures and processes which allow an individual to think, imagine, interact with, and communicate about space" (Medyckyj-Scott \& Blades, 1992, p. 217). The way that humans remember and communicate spatial knowledge is 
related to the three components introduced in the previous section (Peuquet, 2002). People can mentally conjure images of locations, retrace routes in their minds, and verbally describe the layout of an area. These three mental constructs are referred to as schema, cognitive maps and language. Schema help individuals to classify the type of place they are visiting, providing a declarative level of knowledge. Cognitive maps allow individuals to navigate through an environment, resulting in a procedural level of knowledge. Language enables people to describe spatial relationships, permitting a configurational level of knowledge and an understanding of

abstract concepts (Medyckyj-Scott \& Blades, 1992). These three mental constructs are rooted in the prior knowledge and experience that people bring to a site. Visitors build upon this knowledge base by incorporating new experiences that occur through both direct and indirect interactions with the environment (Peuquet, 2002). An understanding of these three mental constructs will enable interpreters to facilitate the spatial learning process.

\section{$\underline{\text { Schema }}$}

Schema representations provide blueprints or frameworks that allow people to identify an unfamiliar setting (Medyckyj-Scott \& Blades, 1992). Individuals categorize a place based on their idea of what that place should look like (Peuquet, 2002). For instance, a person from the eastern U.S. may have one idea of what a mountain looks like, while a person from the western U.S. may have a very different idea of what a mountain looks like. A visitor from the west may thus look at the smaller, gentler mountains of the east and categorize them as hills. Schema representations are abstractions of the features common to many different but similar environments (Medyckyj-Scott \& Blades, 1992). This allows individuals to imagine a space they have not seen by applying this mental blueprint when visualizing the environment. For example, the schema for a National Forest may conjure an image of trees, trails, camping sites 
and ranger stations. Schema representations are fundamental to the human experience of the world and are so ubiquitous that they are typically taken for granted (Peuquet, 2002). Interpreters may be able to tap into the mental schema of visitors to aid in the communication of spatial concepts.

\section{$\underline{\text { Cognitive Maps }}$}

Cognitive maps allow people to orient themselves within a landscape and to navigate through an environment. These mental maps also allow people to devise shortcuts and give directions to others (Golledge \& Stimson, 1997). The ability of people to sketch cognitive maps has led to their widespread use in research on spatial knowledge. Sketch maps have been used to gather data on recreational use patterns and impacts on hiking trails (Lankford, Scholl, Pfister, Lankford, \& Williams, 2004); environmental learning of first-time travelers (Guy et. al., 1990); tourists' spatial conceptions of large-scale environments (Young, 1999); and spatial knowledge of the visually impaired (Jacobson, 1998). Despite their widespread use, cognitive maps have been criticized for their limitations in accurately representing people's spatial knowledge. Golledge and Stimson (1997) suggested that the term cognitive map is really just a metaphor, since these mental representations of space are not equivalent to cartographic maps. Cognitive maps are typically simplified, incomplete, distorted representations of the environment that include attribute information about certain places. In other words, people don't remember landmarks and paths as georeferenced points and lines on a map. Instead, people store attribute information about the appearance and significance of places. Imagery and schema become embedded within a person's cognitive map (Peuquet, 2002). The implication for interpretive design is that imagery should be used in conjunction with maps to help visitors retain spatial information. 


\section{$\underline{\text { Language }}$}

The third mental construct is language, which imposes a framework on how people think about space. Metaphor, analogy, and descriptive phrasing carry implicit information that may contribute to a person's mental representation of space (Medyckyj-Scott \& Blades, 1992). In addition, "language often conveys far more meaning than the mere sum of the words - in evoking mood, emotion, and imagery, as well as other meaning that may not be represented in any literal sense" (Peuquet, 2002, p. 177). Environmental representations are also tied to people's values and belief systems, which control the way individuals interpret the meaning of a space (Golledge \& Stimson, 1997). Thus, the language used to convey a specific spatial concept must be carefully worded in order to communicate the desired meaning. The power of language is in its ability to describe abstract spatial concepts and to encourage people to employ visualization techniques. Individuals have an innate ability to visualize an unseen environment, imagine traveling along a route, picture themselves at a specific location, and rotate mental imagery to look at an area from a different point of view (Kitchin, 1997). In addition, metaphors and analogies can be used to relate the unknown to the interests and prior experiences of visitors (Ham, 1992). Together with imagery and maps, language can be used as a tool for facilitating spatial learning through the application of indirect experiences. 


\section{Indirect Experience of Space}

The role of geointerpretation is to offer opportunities to experience environments indirectly through the design and implementation of secondary sources of spatial knowledge. Experiencing large landscapes holistically is difficult; therefore, indirect experiences can facilitate the development of a configurational level of knowledge. Golledge and Stimson (1997) held that representations of an environment fulfill certain functions that cannot be served by direct experience alone. Furthermore, secondary sources of information allow spatial knowledge to be acquired faster (Peuquet, 2002). The media used to communicate spatial concepts should serve the following functions: motivation, demonstration, putting in context, and construction (Dransch, 2000). As a motivator, interpretive media peaks the interest of visitors and encourages them to learn. Media can then demonstrate spatial phenomenon, provide a spatial context for an occurrence, and enable the construction of mental maps and models. Thus, it can be seen that interpretive media fit easily within the declarative $\rightarrow$ procedural $\rightarrow$ configurational sequence of acquiring spatial knowledge. Specific techniques for communicating spatial concepts can now be devised based on this theoretical foundation.

A map may be the only thing a visitor ever looks at while visiting a park and should therefore be designed with the utmost care. A visitor study at Yosemite National Park found that $90 \%$ of the visitor groups surveyed used the park brochure/map, while only $25 \%$ used exhibits and $8 \%$ attended a ranger-led talk (Littlejohn, Meldrum, \& Hollenhorst, 2006). These results are typical of what NPS visitor use surveys have found. Interpretive planners should ask themselves, "If this is our only opportunity to communicate a message to a visitor, what do we want to say?" Maps are not typically thought of as interpretive media, but instead as planning and management tools. As an example, the Bibliography of Interpretive Resources lists articles about the design 
of visitor maps and the use of living maps under the heading of "Management and Administration" (Basman, 2003). Similarly, Ham (1992) defined a thematic map as a conceptual plan used for designing self-guided trails. These planning maps identify the overall theme of a self-guided trail and the sub-themes of the various stops. Yet themes can be developed for all visitor maps, and they should cease to be thought of as merely planning and management tools. To facilitate this, Ham's (1992) framework for planning and preparing exhibits will be adapted for use in the design and implementation of geointerpretation. This framework is composed of the following seven elements: exhibit type, theme, levels, design, text, visuals, and interaction. Type

Maps and models are miniature representations of the world around us. Space can be represented in a multitude of ways and interpretive planners must first determine the type of spatial representation that is desired. Flat maps are two-dimensional representations of space, topographic models are three-dimensional, and animations include the dimension of time (Peuquet, 2002). In addition, the vantage point of the representation must be chosen - a birdseye, profile, panoramic or oblique view all provide differing views of an area. Research indicates that the 60 -degree oblique view is a preferred representation because it is considered to be the most realistic (Arthur \& Passini, 1992). Another consideration is frame of reference, which denotes whether a map is oriented to the visitor, a local setting, or a global coordinate system (Peuquet, 2002). Research indicates that You-Are-Here type maps should be aligned to the terrain, because they are much easier for visitors to use (Levine, Marchon, \& Hanley, 1984). Finally, the focus of attention allows planners to decide which elements within a landscape will be highlighted. The scale of the representation can be adjusted to focus on a small area or a 
larger region. This can direct the attention of the visitor to a single element or a group of elements within a landscape (Peuquet, 2002).

The size of the spatial representation must also be considered in the design of geointerpretation. Large and small spaces can be thought of as environmental space and object space, respectively. Object space is smaller than a human being, while environmental space is larger than a human and cannot be manipulated. Maps and computer screens are essentially misrepresentations of large spaces, because the scale is greatly reduced and people are able to manipulate these representations as though they are small spaces (Freundschuh \& Egenhofer, 1997). The key to overcoming people's misconceptions of large spaces may be to increase the size of the map or display used to communicate spatial knowledge. Freundschuh and Egenhofer (1997) suggested that wall-size displays are better suited to helping people understand large spaces. Similarly, the living maps developed by Bremen et.al. (1992) used room-size representations to more accurately represent scale. Thus, spatial concepts may be more effectively communicated using representations that are large enough to go beyond object space. All of these factors should be considered when determining the type of spatial representation that will be used to interpret a site.

\section{Theme}

The space portrayed on a map has a meaning that may not be readily evident to visitors. The role of geointerpretation is to provide a connection between visitors and this space. Themes are the mainstay of interpretation, and a map can convey a theme similar to an exhibit or interpretive program. Maps that are strictly created to be reference tools may be missed interpretive opportunities. These tools can do so much more than just show visitors how to find the restrooms. In fact, Andrews (1983) argued that there is no limit to the subject matter that can 
be portrayed on thematic maps, and they should be used for more than just providing information on the locations of places. In addition, Kealy (1998) advocated the creation of interpretive maps that are designed to communicate meaning by including only those features that are related to the theme. This is not to say that visitors don't need reference maps to show them the location of the restrooms. However, even this type of map can be designed to communicate a theme. For instance, a map might convey the theme - The Visitor is an Important Part of the Landscape. This map would show the visitor how they will be integrated into the landscape through systems of trails and other amenities. In addition, visitors could be encouraged to act as a steward for the area, since they are an integral part of this space.

Developing themes for maps may seem daunting at first, but the theme may present itself naturally after a series of questions are answered: What is the significance of the area that is to be mapped? How have the individual places and paths interacted over time? What meaning emerges from these interactions? What makes this area unique, or conversely - universal? Why should visitors want to explore this space? Was this space created by a certain phenomenon? Does this space provide the context for an event? How does this space relate to the daily lives of visitors? How does the meaning at this scale differ from other scales? Does the configuration of this area influence human or natural processes? What would be different if this space was altered? Has this space always appeared the way it does today? Why is this space important? The answers to many of these questions are probably already being interpreted by other means hence, the spatial component can be easily incorporated into existing programs and exhibits. Geographic interpretation thus has the potential to increase understanding of the significance of any site. A map may be the only thing a visitor ever looks at while visiting a park - this is an interpretive opportunity that should not be missed. 
$\underline{\text { Levels }}$

Exhibits succeed by breaking information down into small, easily digestible pieces. Ham (1992) defines these pieces as levels, or the conceptual components of an exhibit. He recommends incorporating four distinct levels into the design of each exhibit sign or panel. Similarly, maps can benefit from breaking down information into smaller chunks that are easier for visitors to process. Maps are inherently complex, yet all of the information they contain is presented simultaneously to the viewer (Thorndyke \& Stasz, 1980). The thematic title and individual map components (points, lines and areas) provide a logical way for breaking down map displays into four levels. Recall Bertin's (1981) levels of information presented earlier: elementary, intermediate and overall information. Portraying each of these components sequentially rather than simultaneously may keep the visitor from being overwhelmed when they look at a map. Thorndyke and Stasz (1980) found that individuals who partition maps into conceptual categories or smaller regions are more likely to understand spatial relationships among map features. As previously established in this paper, at least three experiences may be needed for a person to achieve an overall or configurational level of knowledge. Using levels to allow visitors to experience the map in three different ways may require three panels in a brochure, three signs, three models, three sub-themes in an interpretive program, or a combination of these techniques. Breaking down complex spatial information into its various components can help visitors progress from an elementary level of knowledge to an overall level, which Bertin (1981) argues is the main purpose of graphics such as maps.

\section{$\underline{\text { Design }}$}

The design of an interpretive exhibit determines how aesthetically pleasing an exhibit is and how easy it is to read and understand. Designing maps is challenging because of the spatial 
nature of the information and the numerous cartographic conventions that exist. For instance, multiple graphical variables can be used to symbolize geographic information. These include the size, value, color, shape, texture, arrangement and orientation of point, line and area symbols (Longley et. al., 2005). In addition, the placement of map titles, legends, scale bars and feature labels must also be considered. Cartographic design is challenging because people's response to graphical symbols may be unexpected and produce unintended results. For instance, mapreaders may accept printed color as a representation of true color. People may assume that an area feature presented as green represents leaves and grass, while a light brown area is associated with sand (Shemyakin, 1962). Due to these issues, map designers should be well versed in the skills of cartographic design. Desktop publishing programs and geographic information systems enable anyone to make maps. To create truly effective communication tools, the map designer requires some degree of cartographic knowledge.

\section{$\underline{\text { Text }}$}

Exhibit text focuses the visitor's attention on specific elements within the display and relates a story about these elements (Ham, 1992). In addition, text supports the double encoding of spatial knowledge, which occurs when people store information both verbally and visually. Research indicates that double encoding improves people's ability to remember information (Dransch, 2000). Verbal descriptions of the spatial relationships in maps may help visitors acquire a configurational level of knowledge and an understanding of abstract spatial concepts. For example, a visitor may look at an image of a landscape without ever noticing spatial patterns and relationships. A verbal description of the landscape portrayed by the image may allow the visitor to recognize how the arrangement of features contributes to a certain phenomenon. Denhiere and Denis (1989) found that when text is used to describe spatial configurations, the 
order in which the statements are presented is crucial. Since the description may begin at any point on the map, the researchers experimented with using different anchorpoints and describing the layout in different orders. They discovered that descriptions that started on the left (or west) side of the map and moved horizontally across the map produced the highest recall frequencies. Thus, text that describes elements within a map should be presented systematically, as though the visitor is reading the map from left to right and down the page. In this manner, text can enable a visitor to read the stories that are hidden within maps and the landscapes they represent.

$\underline{\text { Visuals }}$

Visuals are powerful communicators and can add interest to an exhibit (Ham, 1992). While maps are often used as visuals within an exhibit, the map itself can benefit from the addition of visual elements. For instance, Thorndyke and Stasz (1980) found that pattern encoding is an effective technique for learning the configuration of a map. This involves seeking out shapes or patterns created by elements within a map that can be used as mnemonics for remembering spatial information. For instance, astronomers seek out patterns or constellations in the stars to aid people in navigating the night sky. Interpretation could be used to help visitors see a map in a different way by identifying interesting patterns within the map.

Galliano and Loeffler (1999) lamented that compared to the beautifully illustrated maps of past centuries, modern maps portray nothing of the character of a place. Maps can thus benefit from the application of a little creativity and artistic design. Harmon (2004) illustrates this point by considering maps as a singular form of art. The author writes,

Maps intrigue us, perhaps none more than those that ignore mapping conventions. These are maps that find their essence in some other goal than just taking us from point $A$ to point B. They are a vehicle for the imagination, fueled up and ready to go (p. 10). 
Harmon's (2004) book includes a map of Scotland made to look like a man in a kilt, topographic maps of the human face, a map created from the point of view of a dog, and numerous other non-traditional maps. These techniques can be used to add visual interest to interpretive maps and make learning spatial information fun and interesting.

Educational researchers have studied the effects of replacing the symbolic elements of maps with pictorial elements. In a study by Abel and Kulhavy (1986), line drawings were used to represent the location of features instead of traditional geometric symbols. The map used for the study was a representation of a fictitious island. The drawings were of a beach, river, mountains, trees, turtles, and a number of other features. While the students studied the map, they read or listened to a story that described the configuration of the island. The participants were then asked to reconstruct the island from memory by indicating the location of features on a blank map and labeling each feature. The results were compared to another group that studied a map with geometric symbols. The findings indicated a significant difference between the groups due to the superior performance of the students that received the picture map. Thus, adding visual elements to a map can be an effective technique for helping youth remember spatial information. Further study is needed to see if this technique similarly benefits adults. In designing exhibits, Ham (1992) advises planners to consider whether a visual might work better than a word. Likewise, map designers might consider whether a visual might be more effective than a symbol.

\section{$\underline{\text { Interaction }}$}

One way to communicate spatial concepts through multiple experiences is to encourage participation of the visitor. Redvale and Dickey (1995) defined three levels of visitor involvement: hands-on, interactive and active participation. A hands-on display allows the 
visitor some level of tactile contact. A paper map is hands-on in that it permits the visitor to pick it up, rotate it, and orient it to the landscape. An interactive exhibit responds to an action by a visitor, such as the pulling of a lever. A topographic model that lights up the location of a landmark when the visitor pushes the appropriate button is an example. Finally, active participation encourages the visitor to explore the effects of different variables in making something happen. An example is a computer simulation that alters the spread of wildland fire based on humidity, temperature, wind direction, and the slope of a hill. The visitor is able to observe the changes as they alter the conditions of each of the variables. The use of these three approaches may be improved by adopting techniques that have been devised by other disciplines for communicating spatial information.

\section{$\underline{\text { Hands-on }}$}

Hands-on interpretive experiences allow the visitor to engage the sense of touch coupled with the sense of sight. As mentioned previously, the simplest hands-on involvement is allowing the visitor to physically hold a map and rotate it until it is oriented to some place in the landscape. Research shows that the alignment of a map to the setting is crucial in wayfinding and the learning of routes (Arthur \& Passini, 1992). This technique has proven more effective in spatial learning than the orientation of a map to a more abstract frame of reference such as north/south/east/west (Warren \& Scott, 1993). Thus, the design of interpretive maps should take into consideration the alignment of the visitor to the landscape when they receive the map. For instance, a visitor entering a large park from the north will have a different perspective than a visitor entering from the south. Research indicates that people associate the top part of a map with forward movement (Levine et. al., 1984). People may therefore compensate by rotating the map, but this renders the textual information illegible because it is upside down. Printing maps 
oriented to different entry points may be useful in helping the visitor navigate in an unfamiliar environment.

Stationary maps mounted on a sign, tabletop or exhibit panel can also be made hands-on by the use of pointing devices. When communicating information about the environment, pointing focuses attention on a place and is the simplest and most effective way of indicating direction (Golledge \& Stimson, 1997). A light pen or stick may be used to locate specific areas within a map. Similarly, attaching a pointing device to a sign that labels features in the environment may allow visitors to align the actual feature with the image on the sign. Pointing is a technique that could also be easily incorporated into interpretive programs by allowing visitors to participate in locating and pointing out features and their spatial relationships. Thinking of maps as another type of hands-on experience reinforces the idea that maps should be designed with the same care afforded other interpretive products.

\section{$\underline{\text { Interactive }}$}

Environmental learning is an interactive process that is facilitated by either direct experience with an actual environment or a representation of that environment. This interaction should involve sensory perception, allowing a person to feel like they are moving through space. This can be accomplished vicariously by interacting with maps and models (Downs \& Stea, 1977). For instance, visitors can use interactive play to take simulated trips over a map, enabling them to learn locations, routes and layouts in the process (Shemyakin, 1962). The living map concept is an example of a program that allows visitors to learn through interactive play. Props are added to and moved about on the map, allowing the participants to immerse themselves within the space portrayed by the map (Bremen et. al., 1992). In parts of the world where imagery, printed maps and computers are not readily available, children acquire spatial 
knowledge through this type of play. These children develop advanced spatial cognition by creating environmental modeling toys from simple objects like blocks and stones. Adults can also use environmental modeling toys to accomplish spatial tasks, simulate travel, or play games with a spatial component (Downs \& Stea, 1977). Geointerpretation can thus facilitate interaction and environmental learning using simple props and existing maps.

\section{Active participation}

Active participation allows visitors to initiate changes in spatial relationships by manipulating different variables. The complexity of these models usually requires computer programs that can quickly and accurately display the effects of a visitor's inputs. For example, Gyllenhaal and Perry (1998) evaluated a computer program at the Museum of Minnesota that allowed visitors to manipulate climatic systems. This program represented three distinct spaces: 1) weather patterns across the surface of the earth, 2) cloud structure through the earth's atmospheric layers, and 3) the space between the earth and the sun. The researchers evaluated the pattern of use exhibited by visitors and found that people progressed through three distinct stages as they participated in the experience. These stages are similar in nature to the declarative $\rightarrow$ procedural $\rightarrow$ configurational sequence discussed previously. Visitors began the experience with an exploratory phase, determining what the purpose of the program was and what the interface devices did. The second stage involved broadly-focused play, with the visitors figuring out the procedure for operating the program and manipulating the variables through trial-and-error. In the final stage, users entered goal-directed play in which they began to understand the relationships between the variables. Visitors were now able to purposefully manipulate the variables to achieve specific goals. 
The researchers' identified a number of lessons learned based on an evaluation of the effectiveness of the Atmospheric Explorations computer program (Gyllenhaal \& Perry, 1998). First, observers noted that very few visitors referred to the help screens that were designed to explain the scientific concepts of climate and weather. This suggests that this information should be integrated into the main part of the program to make sure the user understands why the variables interrelate in a certain manner. Secondly, visitors had difficulty describing the models in words - an argument for double encoding the experience with both visual imagery and verbal explanations. Third, most visitors were unable to relate the experience to their daily lives, despite the fact that weather affects everyone. This demonstrates the need for clearly defined themes that provide a connection between the meaning of a space and the interests of the visitor. Finally, researchers discovered that visitors frequently misunderstood the earth/sun relationship. To make the effects of tilt and orbit more obvious to visitors, the earth/sun system was not shown to scale, contributing to this misconception. This emphasizes the difficulty people have with spatial concepts and the importance of representing scale accurately. Computer systems are valuable tools for teaching complex spatial concepts and great care must be taken in designing this type of experience.

Web-based spatial information is another valuable tool for creating spatial experiences. Web programs like Google Earth offer the user the unprecedented ability of being able to travel through the environment in virtual space. Peuquet (2002) stated that the use of virtual worlds is blurring the distinction between direct and indirect experience. A computer with internet capability in a visitor center can enable a person to explore the area from a variety of different directions and vantage points. Google Earth and similar systems allow users to rotate the landscape to achieve a birds-eye or oblique view of an area while moving between places and 
traveling simulated routes. This can be a powerful tool for learning the configuration of a landscape; however, there are certain issues that must be addressed. First, the resolution of the imagery depicting natural areas is quite often not nearly as high as the resolution of urban areas. Thus, not all sites will be represented adequately. In addition, on-line databases are typically exploratory in nature (Peuquet, 2002). Variables usually cannot be manipulated and no thematic message is conveyed. Themes may therefore need to be presented external to the computer environment.

Synthesis

The meaning of the space within a drop of water and the interactions that occur within that space are very different from the space and interactions within a watershed. Interpreters seeking a new idea for an exhibit or program may only need to think of their site at a different scale. Interpretation can thus be considered "a communication process that forges emotional and intellectual connections between the interests of the audience and the inherent meanings in the resource [at a variety of scales]" (Basman, 2003, p. ix). The National Association of Interpretation's definition can thus be extended to encompass the importance of space and scale. Specific techniques for communicating with visitors about large-scale spaces may help visitors to understand natural resource management issues that affect large landscapes.

To this end, the literature reviewed in this section answered the following research questions: How is spatial knowledge acquired? How can interpretation be used to effectively communicate geographic information? The extensive work conducted in the fields of geography, environmental psychology and education provide a thorough theoretical and empirical basis on which to base strategies for interpretation. The principles of geographic interpretation outlined in this section may prove useful in increasing the understanding of any 
site. These principles include: 1) guiding people through the declarative, procedural and configurational levels of spatial knowledge (Golledge \& Stimson, 1997) and 2) designing spatial representations as though they are exhibits - considering type, theme, levels, design, text, visuals and interaction (Ham, 1992). Specific research on how people relate to large spaces is needed to provide managers with a starting point for designing geointerpretation. An exploratory study of this nature is reported in the following section. 


\section{Methodology}

\section{Visitor Study}

Purpose of Study

The purpose of this research project was to examine the role of spatial knowledge in the management of natural resources. The objective of this aspect of the study was to study visitors' mental images of National Forests and perceptions of fire size. These visitors were asked questions about their cognitive representations of forest environments and their perceptions of the size of a recent fire.

\section{$\underline{\text { Research Design }}$}

The design of this research project was based on the following methods:

Spatial schema - A generalized "blueprint" of the structure of an environment. Visitors were asked questions about their cognitive representation of a forest landscape.

Language - $\quad$ Language imposes a framework on the way people think about space. Visitors were asked to indicate perceptions of fire size after being shown one of four statements. Each statement conveyed the same information using different wording.

Cognitive Maps - Images of the environment that people form based on direct or indirect experience. Visitors were asked to sketch an outline on a map representing their perception of the size of a recent fire.

\section{$\underline{\text { Research Questions }}$}

The following research questions were addressed by this study:

a) What are visitors' mental representations of forest environments?

b) Do visitors understand descriptions of fire size?

c) Do male and female visitors have different perceptions of fire size?

d) Does the language used to describe fire influence perceptions of fire size? 


\section{$\underline{\text { Survey Design }}$}

Surveys have been used repeatedly by researchers (Cortner et. al., 1984; Gardner et. al., 1985; Manfredo, 1990) to test knowledge of fire effects and attitudes towards fire management. Typically, the survey questions are based on the following topics:

1) Knowledge about the ecological effects of fire,

2) Understanding of the effects of fire management (suppression, prescribed fire),

3) Acceptance of fire management techniques, and

3) Response to policy statements

Much of this work is based on the survey developed by Stankey (1976) that asked visitors questions about the role of fire and required respondents to choose a management strategy from among nine statements. In this survey, one knowledge question pertained to fire size (The majority of forest fires that occurred in the Rocky Mountains before the pioneers covered hundreds of thousands of acres). Another knowledge question pertained to forest patterns (Forest fires are partly responsible for some of the open meadows and grassy fields one finds in the Northern Rocky Mountains). The question about fire size scored the lowest out of the eleven questions ( $23 \%$ answered correctly), while the question pertaining to forest patterns was comparable to many of the other questions ( $54 \%$ answered correctly).

McCool and Stankey (1986) replicated this study thirteen years later and found significant improvement in the number of correct responses for seven of the questions including the questions about forest patterns - but response to the size question was relatively unchanged (26\%). It cannot be determined from these results if the misconception is based on a lack of spatial knowledge or a lack of historical knowledge. Thus, the aim of the current study was to focus on the spatial component by asking participants about their perception of the size of a more recent fire. In addition, questions pertaining to forest patterns at both the stand and landscape level were presented. 
Within the natural resource management literature, forest patterns have typically been examined in the context of scenery management. Researchers have tested people's responses to the visual qualities of forests by using sets of photographs to represent various types of scenery and forest composition. Visitors indicated their preference by selecting the photo they found to be the most visually pleasing. The number of choices presented to the visitor is limited, often to only three photographs (Taylor \& Daniel, 1985; Scott, 1998; Englin et. al., 2001). This is restrictive, in that other variables that contribute to the perceptions of visitors may be discounted by this method.

This study aimed to extend this research by drawing out the visual imagery and schema representations of visitors. An open-ended question allowed participants to describe their mental image of a National Forest. A similar question was used by Cortner et.al. (1984) and Carpenter et. al. (1986) to draw out imagery of a forest fire (What comes to mind when you think of a fire in a pine forest?). This was followed by five questions designed to specifically focus on the spatial and structural characteristics of forests. Vaux et. al. (1984) reviewed studies of the scenic quality of forests affected by insects, fire and logging and concluded that the attractiveness of forests is based on the spatial quality of the stands. Palmer and Sena (1992) took this one step further and consolidated the results of twenty-four different studies on the scenic value of forests. Based on this summary, the authors defined eight structural characteristics related to visual quality (age structure, spatial distribution, vertical structure, canopy openings, species composition, large tree dominance, herbaceous ground cover, and downed wood). For the purpose of the current study, these categories were collapsed into four (tree size, understory, species composition, and spatial distribution). The first three were considered at the stand level, and the spatial distribution category was investigated at the landscape level. 
A final question related to National Forests was asked to assess visitor attitudes towards fire management. The acceptability of the amount of area that has burned in the National Forests over the past 20 years (from about the time of the 1988 Yellowstone fire) was assessed. The participant's focus was then redirected from a national level to a more local level by asking them to consider a fire that occurred within the Columbia River Gorge National Scenic Area (CRGNSA). This was accomplished by presenting visitors with a randomly selected flash card that contained a map of the CRGNSA and indicated the approximate location of the fire. In addition, visitors received one of four statements about the fire and its effects. The wording of the statements reflected various combinations of descriptors (immense, burned through, and devastated). The language used to depict fires in media reports is generally negative (i.e. destroyed vs. cleansed), and the hypothesis is that this language may influence both perceptions of the size of the fire and attitudes towards fire management (Carpenter, et.al., 1986; Reid, 1989). Jacobson et. al. (2001) found that "public opinion about the benefits of prescribed fire matched closely the benefits identified by the media" (p. 934). It follows that public opinion may also be influenced by reports of the detrimental effects of fire.

Participants were told the size of the fire (370-acres) and then asked to draw an outline of the fire on an aerial photograph to indicate their perception of its size. This fire, known as the Herman Creek fire, was chosen both for its level of impact (see Study Location) and its relatively small size. A smaller area may be easier for a person to relate to than an area measuring in the tens or hundreds of thousands of acres. An aerial photograph was chosen instead of a map to continue the focus on mental imagery and because visitors have various levels of map reading ability. In addition, it has been suggested that people are familiar with aerial and satellite imagery and that they are easy to understand by most everyone (Evans et.al., 1999). Prominent 
features were labeled and a scale bar was included to ensure the representation was fully understood. This method mimics that used by Galliano and Loeffler (1999) of using a map of the general area (presented on the flash card) to orient the visitor, followed by a close-up view of the test area. A 1:24,000 scale was chosen because it allowed for the perimeter to be easily drawn by the visitor while also allowing room for variation (both larger and smaller than the actual size of the fire). A black dot indicating the approximate location of the fire provided a starting point for the drawing. This allowed the perimeters to be easily lined up when they were digitized and analyzed.

In addition to comparing groups of visitors according to the language they received, comparisons were made between male and female visitors. Sex differences in spatial performance have long been observed in research on spatial abilities. The explanations for these differences were summarized by the National Research Council (2006). Differences between the sexes in terms of spatial ability has been attributed to a combination of both biological (nature) and experiential (nurture) factors. Biological differences are thought to cause males and females to seek out different experiences, such as exploring or playing with spatial toys versus playing at home-type activities. The nurture effect argues that socialization patterns further emphasize this difference by encouraging males to engage in activities that promote better spatial skills. Thus, comparisons were made to see if sex differences affected perceptions of fire size.

The next questions asked visitors to rate their level of knowledge and the availability of information about the Herman Creek fire using a semantic differential scale. Finally, the survey concluded with a question regarding the acceptability of the amount of area burned by the Herman Creek fire. The choices were a repeat of the statements provided earlier in the survey to 
assess acceptability of the amount of area burned in the National Forests as a whole. A copy of the survey is presented in Appendix A.

\section{Study Location}

The Columbia River Gorge National Scenic Area (CRGNSA) is located on the border between Oregon and Washington, spanning a distance of 80 miles and extending up to 4,000 feet in depth. The river canyon is the only sea level route through the Cascade Mountains and is therefore an important transportation corridor. The Bonneville Dam provides hydropower to the northwest region and the scenic area abounds with recreational opportunities. To the north of the gorge is the Gifford Pinchot National Forest, and the Hood River National Forest is located to the south. The CRGNSA is managed under the National Scenic Area Act - offering protection to the scenic, natural, cultural, recreational and economic resources afforded by the region.

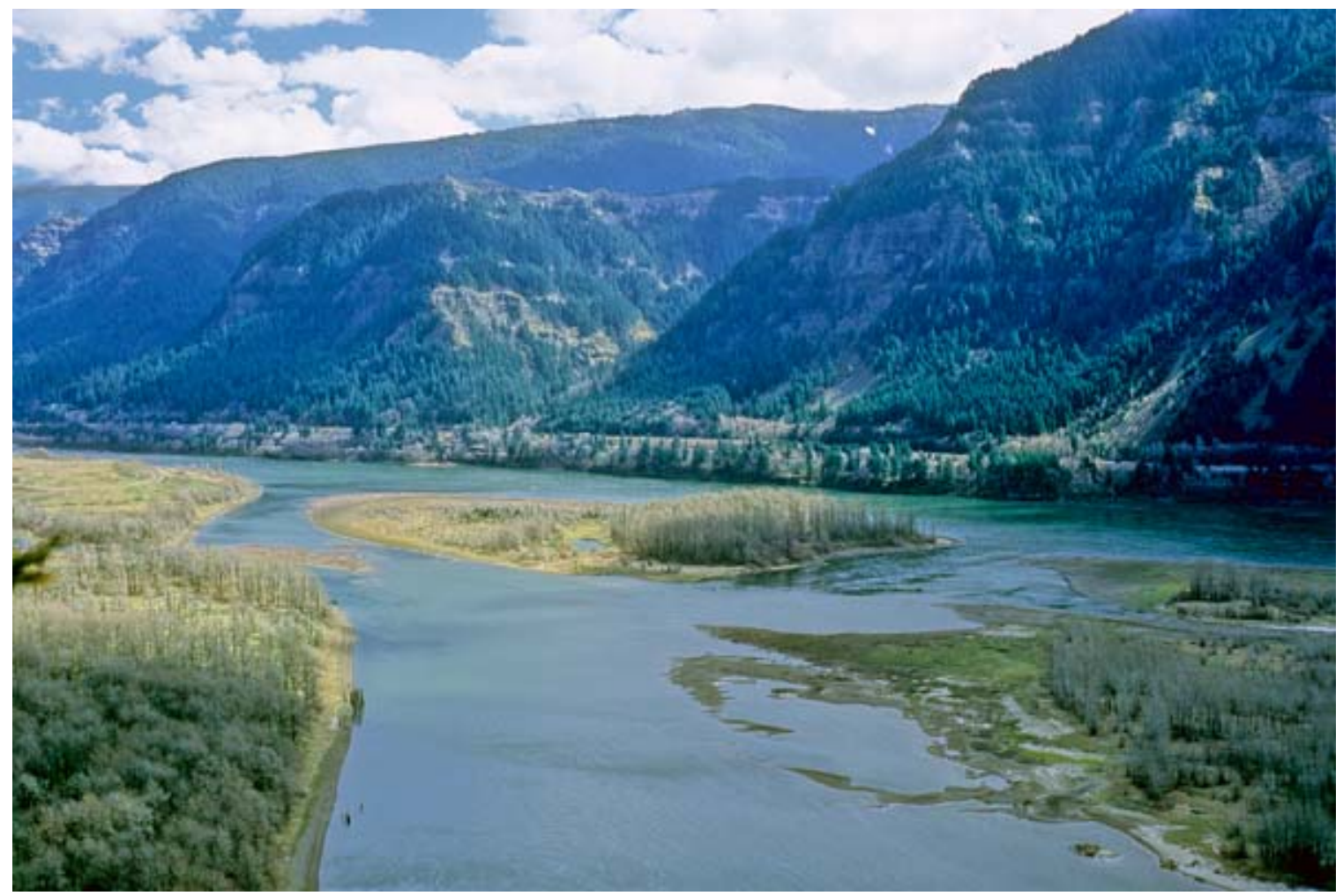

Figure 1 The Columbia River Gorge National Scenic Area 
In early September of 2003, the Herman Creek Fire ignited from a downed power line in the CRGNSA, creating a significant impact to the local population. A 47-mile stretch of Interstate- 84 was closed, causing traffic problems as far away as Portland, Oregon. In addition, Union Pacific Railroad was forced to delay its trains and sixty people were evacuated from the small tourist town of Cascade Locks. The mayor placed the entire town of over 1,000 residents on alert for possible evacuation. Smoke and flames were clearly visible and residents feared they would lose their homes. The town lost power and a bed-and-breakfast business and two other structures burned to the ground. The Herman Creek fire received a lot of news coverage due to the significant impact of the fire on this highly visited and traversed recreation area. The fire's high profile and recent occurrence contributed to its selection for this study.

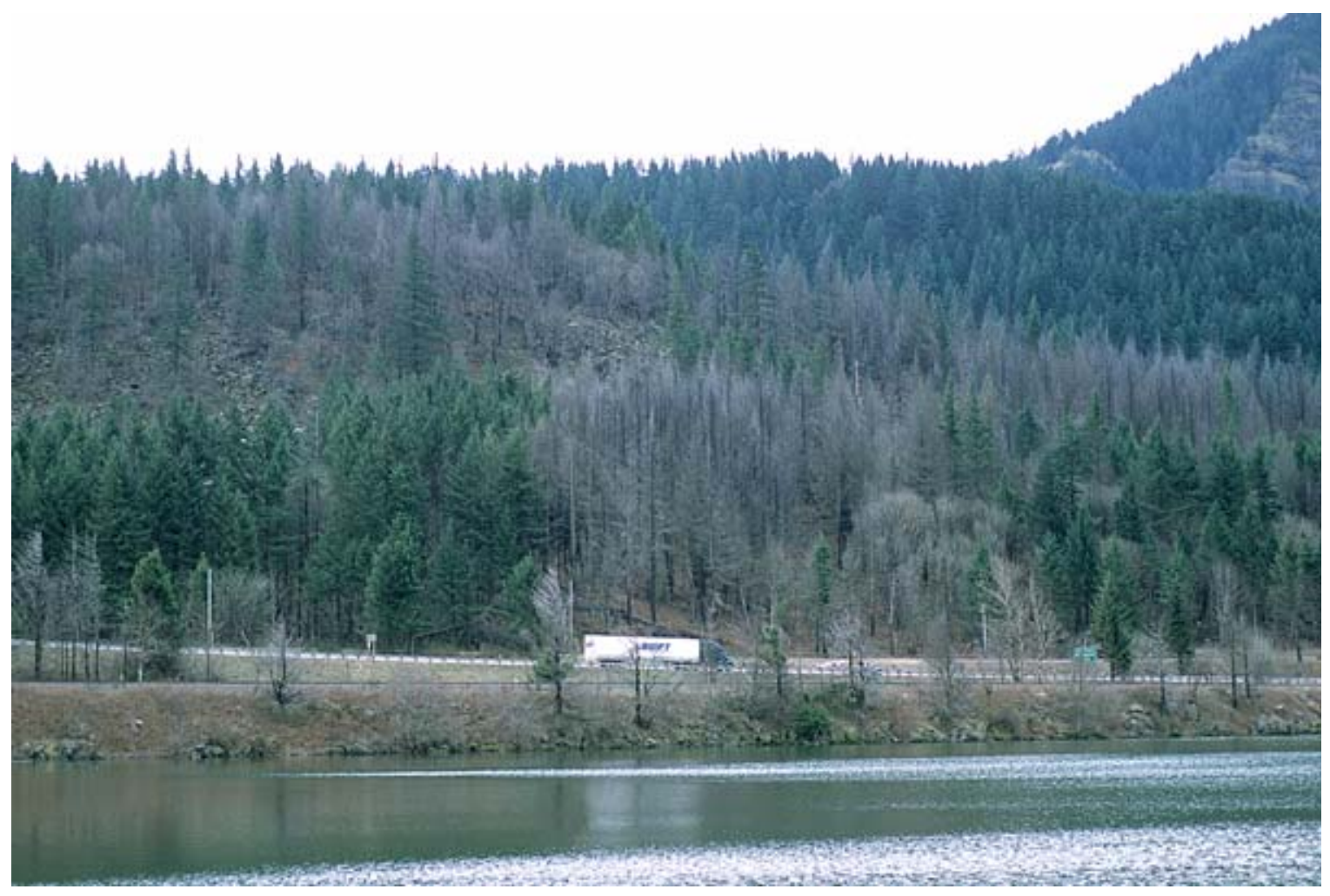

Figure 2 The Herman Creek fire burned across Interstate-84. 


\section{Spatial Data Sources}

The data for the overview map of the CRGNSA was obtained from the Columbia River Gorge National Scenic Area Data Distribution Facility. The Forest Service's Pacific Northwest Region maintains the data and makes it available to the public via the web. The map was created using the state boundary, urban areas, and scenic area boundary coverages. The files were projected using UTM Zone 10, NAD 27 and were presented at a scale of 1:754,050.

The data for the aerial photograph of the Herman Creek area was obtained from the Oregon Geospatial Enterprise Office via the web. A digital orthophoto was chosen in order to eliminate the distortions that occur in a conventional image. Orthophotos are aerial photographs that have been rectified to eliminate the effects of camera tilt and terrain relief. This gives the image a uniform scale, allowing distance and area to be measured. A digital orthophoto can therefore be used just like a traditional map. A shapefile of the Oregon highway system was overlaid on the image to emphasize the location of Interstate 84 . Both files were projected using the Oregon centered Lambert map projection and were presented at a scale of 1:24,000.

\section{Data Collection Procedures}

This study used a mixed-methods approach to assessing and analyzing visitors' mental representations of forest environments and their perceptions of fire size. A survey with both closed (quantitative) and open-ended (qualitative) questions were used to assess visitors' mental images of forest environments. A spatial representation (air photo with GIS overlays) of the location of a recent forest fire was presented to allow visitors to draw their perceptions of the size of the fire. Visitors participated in the schema questionnaire, the mapping task, or both depending on visitor time constraints. The surveys were completed between March 4 and April 3, 2006 on eleven different dates. This study was accomplished in conjunction with the National 
Visitor Use Monitoring project, which employed a stratified random sampling approach by date, time block and site type. Sites were within the Columbia River Gorge National Scenic Area (CRGNSA) and the Mount Hood National Forest and included both day-use developed sites and one general forest area (trailhead). Three of the dates were added based on convenience. The majority of the surveys were completed at Multnomah Falls, a site that receives very high use from the nearby Portland metropolitan area. The participants included visitors and local residents (identified by zip-codes), as well as a few National Forest volunteers. A total of 55 people completed the schema questionnaire and a total of 122 people completed the mapping task. Due to the small sample size relative to the entire population of visitors, caution should by taken when interpreting results.

\section{Limitations}

The data reported here reflects use patterns of visitors to selected sites within the study area during the study period of March - April, 2006. The results do not necessarily apply to visitors at other sites or at different times of the year. In addition, caution is advised when interpreting data with a small sample size relative to the overall population.

\section{Data Analysis}

Analysis was undertaken in a number of steps. First, the open-ended question was analyzed in a qualitative fashion using QDA Miner, a data analysis software package for coding textual data and identifying patterns in coding. An initial coding framework was developed using previous literature on the classification of tourist attractions and forest environments based on spatial and structural characteristics (Wall, 1996; Palmer \& Sena, 1992). These codes were built upon and refined during the analysis process. Final refinements ended with a total of eleven coding categories. Inter-coder reliability was ensured by having two people code all of 
the data separately. Inconsistencies were identified and the two coders discussed and resolved disagreements. In some instances, statements with multiple interpretations were dual coded. Secondly, the closed-ended questions were entered into a standard statistical software package (SPSS). Descriptive statistics were calculated using this program.

The maps were scanned as JPEG files and imported into ArcMap Version 9.1 as a raster dataset. Each map was georeferenced using a first-order polynomial transformation with four control points. The control points were adjusted until the total RMS error for each map was less than or equal to four percent. A polygon shapefile was created for each map and the drawings were digitized using the ArcMap sketch tool. The area of each polygon in square feet was computed using the advanced field calculator and the VBA script code for calculating area. Finally, a conversion factor was applied to convert the area of each polygon to acres. The shapefiles were overlaid in a way similar to the method employed by Uzzell, Pol, and Badenas (2002) to determine how residents defined neighborhoods. In the context of this study, the drawings were overlaid according to statement type and gender, resulting in eight composite maps (Figures $3 \& 4$ ). The acreage figures were then entered and analyzed using SPSS. 


\section{Results}

\section{Schema Representations}

\section{Research Question:}

What are visitors' mental representations of National Forest environments?

\section{Visitor Descriptions of National Forests}

A total of 55 people (25 males and 30 females) completed the schema questionnaire. Participants were distributed fairly evenly in terms of age: $20-29(24 \%) ; 30-39(18 \%) ; 40-49$ $(17 \%) ; 50-59(17 \%) ; 60-69(17 \%) ; 70+(7 \%)$. The majority $(76 \%)$ of the participants were from the local area (<50 miles); 7\% were non-locals from Washington or Oregon; 17\% were from outside of Washington and Oregon. The majority of the participants were from urban (46\%) or suburban (37\%) areas, with only $17 \%$ from rural areas.

The first question asked visitors to describe their mental image of a National Forest. An open-ended approach was used to better capture the depth of visitors' mental representations. Part of the coding framework was developed based on the spatial characteristics of tourist attractions developed by Wall (1996). He divided attractions into three types: point features, linear features, and area features. The second part of the coding framework was developed based on the structural characteristics of forests developed by Palmer and Sena (1992). For the purpose of this study, the eight categories defined by the authors were collapsed into four (tree size, understory, species composition, and spatial distribution). During the coding process, it was discovered that many of the features described by visitors did not fit one of these categories or were related to beliefs or values. Thus, an Other Feature category was created along with three value categories (Symbolic, Aesthetic, Philosophical). Results are listed in Table 3 and coding 
definitions and sample responses are presented in Table 4. The feature that was most often mentioned by visitors was non-spatial (Philosophical $=36$ cases). Large-scale area or landscape features were mentioned by less than half the respondents ( 24 cases). The most often mentioned forest characteristic was species composition (33 cases), while the more spatial characteristics of distribution (12 cases) and vertical structure (13 cases) were the least mentioned.

Table 3 Features of a National Forest

\begin{tabular}{lc}
\hline \multicolumn{1}{c}{ Code } & $\begin{array}{c}\text { Number of cases } \\
(\mathrm{N}=55)\end{array}$ \\
\hline Point Feature (Trees) & 8 \\
Age & 16 \\
Distribution & 12 \\
Vertical & 13 \\
Species & 33 \\
& \\
Linear Feature & 15 \\
Area Feature & 24 \\
Other Feature & 30 \\
& \\
Symbolic & 6 \\
Aesthetic & 25 \\
Philosophical & 36 \\
\hline
\end{tabular}


Table 4 Coding framework and sample responses

\begin{tabular}{|c|c|c|}
\hline Code & Description & Sample Responses \\
\hline $\begin{array}{l}\text { Point Feature } \\
\text { (Trees) }\end{array}$ & References to trees without spatial or aesthetic descriptors. & $\begin{array}{l}\text { Trees } \\
\text { Woods }\end{array}$ \\
\hline Tree Age & $\begin{array}{l}\text { Age structure of trees. Includes descriptions of age (old, } \\
\text { ancient, mature, etc) as well as descriptions of the size of } \\
\text { the tree trunks (diameter, small, big, etc). }\end{array}$ & $\begin{array}{l}\text { Large diameter trees } \\
\text { Some old growth is a bonus } \\
\text { Filled with majestic, giant trees }\end{array}$ \\
\hline Distribution & $\begin{array}{l}\text { The distribution of trees. Includes references to the number } \\
\text { and spacing of individual trees, canopy openings, density, } \\
\text { clustering, etc. }\end{array}$ & $\begin{array}{l}\text { Natural, not organized } \\
\text { Dense trees } \\
\text { Thick forest }\end{array}$ \\
\hline $\begin{array}{l}\text { Vertical } \\
\text { structure }\end{array}$ & $\begin{array}{l}\text { Refers to the height of the trees (tall, towering, etc). } \\
\text { Includes descriptions of various levels of understory and } \\
\text { ground cover. }\end{array}$ & $\begin{array}{l}\text { Many layers and different forms } \\
\text { A variety of upper story evergreen trees } \\
\text { Tall forest }\end{array}$ \\
\hline $\begin{array}{l}\text { Species } \\
\text { Composition }\end{array}$ & $\begin{array}{l}\text { Species composition of vegetation. Response may be } \\
\text { specific (actual species name) or non-specific (i.e. different } \\
\text { or various trees). Includes references to physical } \\
\text { characteristics (leaf type, etc). }\end{array}$ & $\begin{array}{l}\text { Mixture of deciduous and evergreen } \\
\text { Diverse species } \\
\text { Variety of tree types }\end{array}$ \\
\hline $\begin{array}{l}\text { Linear } \\
\text { Feature }\end{array}$ & $\begin{array}{l}\text { Linear features are paths or routes that could be used by } \\
\text { animals or humans to travel through the environment (i.e. } \\
\text { trails, roads, rivers, streams, lakeshores). }\end{array}$ & $\begin{array}{l}\text { A road winding through } \\
\text { Trails through forested areas } \\
\text { Hiking trails }\end{array}$ \\
\hline Area Feature & $\begin{array}{l}\text { Area features are large landscapes such as forests or parks. } \\
\text { Participant may also speak of viewsheds, expanses, } \\
\text { distances, habitats, etc. Includes references to spatial } \\
\text { patterns and variations in the topography or landscape. }\end{array}$ & $\begin{array}{l}\text { Large expanse of trees } \\
\text { Occasional open meadows and broad } \\
\text { views } \\
\text { Varied landscape with trees and water } \\
\text { features }\end{array}$ \\
\hline Other Feature & $\begin{array}{l}\text { This category includes natural features that do not fit into } \\
\text { one of the other feature categories (i.e. wildlife, non-linear } \\
\text { water features, individual landforms, mountains, etc.) }\end{array}$ & $\begin{array}{l}\text { Many living creatures } \\
\text { Mountains } \\
\text { Grey and brown rocks and boulders }\end{array}$ \\
\hline Symbolic & $\begin{array}{l}\text { Includes references to an actual, historical, or fictional } \\
\text { person or character. Also includes symbols (such as the } \\
\text { National Forest logo) and branding (color of signs, etc). }\end{array}$ & $\begin{array}{l}\text { Smokey Bear } \\
\text { Park rangers } \\
\text { Green trucks }\end{array}$ \\
\hline Aesthetic & $\begin{array}{l}\text { Refers to benefits or the type of experience sought (i.e. } \\
\text { solitude, scenery), emotional response, descriptions of } \\
\text { aesthetic beauty, color, sounds, etc. }\end{array}$ & $\begin{array}{l}\text { A green cathedral } \\
\text { Retreat from people, building, density } \\
\text { Excitement, beautiful, quiet, happy }\end{array}$ \\
\hline Philosophical & $\begin{array}{l}\text { Related to land management, such as multiple use, } \\
\text { preservation, conservation, recreational use, protection, } \\
\text { economic benefits, etc. Includes references to types of } \\
\text { activities and level of development. }\end{array}$ & $\begin{array}{l}\text { There should be multiple uses so that } \\
\text { some funds can be generated, but as a } \\
\text { whole the forest should be available for } \\
\text { everyone to enjoy } \\
\text { Untouched preserves }\end{array}$ \\
\hline
\end{tabular}




\section{Visitor Response to Questions on Structural Characteristics of National Forests}

Participants were then asked if their image of a National Forest was based on a region or a specific place. Most people (60\%) stated they were thinking in general or regional terms about their mental image of a National Forest. Of the $40 \%$ who named a specific place, almost half of those named a National Park instead of a National Forest (See Table 5).

Table 5 Mental Image of National Forests

\begin{tabular}{lc}
\hline \multicolumn{1}{c}{ Place or region that comes to mind } & Frequencies \\
\hline Pacific Northwest region & $16.4 \%$ \\
Other region & $3.6 \%$ \\
Pacific Northwest National Forest & $18.2 \%$ \\
Other National Forest & $3.6 \%$ \\
National Park & $18.2 \%$ \\
None & $40 \%$ \\
\hline
\end{tabular}

Results of the closed-ended questions are presented in Table 6. In terms of tree size, only $6 \%$ of people imagined small diameter trees, while $36 \%$ imagined large diameter trees, and 58\% imagined a mix. Eighty percent of the participants imagined dense undergrowth with $20 \%$ imagining the area beneath the trees as clear of vegetation and debris. In regards to species composition, $85 \%$ of participants envisioned two or more types of trees, while $15 \%$ envisioned only one type of tree. Participants primarily visualized a continuous forest pattern (65\%) versus a patchwork pattern (35\%). Perceptions of fire effects indicated that $64 \%$ of the participants believed that groups of trees would survive a fire, and 36\% thought that most trees would appear to have been killed by the fire. 
Table 6 Structural characteristics of National Forests

Characteristic

Tree Size

Small diameter

Large diameter

Equal mix

Undergrowth

Clear of vegetation

Full of vegetation

Species Composition

One type of tree

Two or more types of trees

\section{Frequencies}

$5.5 \%$

$36.4 \%$

$58.2 \%$

$20 \%$

$80 \%$

$14.5 \%$

$85.5 \%$

$65.5 \%$

$34.5 \%$

Patchwork

Effects of Forest Fire

Most trees killed

$36.4 \%$

Groups of trees survive
$63.6 \%$ 


\section{Cognitive Maps}

\section{Research Questions:}

Do visitors understand descriptions of fire size?

Do male and female visitors have different perceptions of fire size?

Does the language used to describe fire affect perceptions of fire size?

\section{$\underline{\text { Visitor Drawings of Fire Size }}$}

Each visitor participating in the cognitive mapping task was presented a card with one of four statements (see Table 7). The location of the Herman Creek fire was pointed out to the visitor using a map of the CRGNSA. An aerial photograph of the Herman Creek area was then presented, the scale bar was pointed out, and the visitor was asked to draw his/her perception of the size of the fire starting at the point indicated on the map. Clarification questions were answered unless they pertained directly to the size of the fire. A total of 122 people completed the mapping task. Of these, 4 were removed from the analysis because the drawings were incomplete or unclear. This resulted in an $\mathrm{N}=118$, with 57 females and 61 males. The first and fourth statements each had an $n=29$, while the second and third statements each had an $n=30$. Maps were overlaid according to sex and statement number (see Figures $3 \& 4$ ).

\section{Table 7 Statements describing the Herman Creek fire}

\begin{tabular}{cl}
\hline Number & \multicolumn{1}{c}{ Statement } \\
\hline 1 & $\begin{array}{l}\text { In 2003, the Herman Creek fire burned through } 370 \text { acres of the Columbia River } \\
\text { Gorge National Scenic Area. } \\
\text { In 2003, the immense Herman Creek fire burned through } 370 \text { acres of the } \\
\text { Columbia River Gorge National Scenic Area. } \\
\text { In 2003, the immense Herman Creek devastated } 370 \text { acres of the Columbia River } \\
\text { Gorge National Scenic Area. } \\
\text { In 2003, the Herman Creek fire devastated } 370 \text { acres of the Columbia River } \\
\text { Gorge National Scenic Area. }\end{array}$ \\
\hline
\end{tabular}



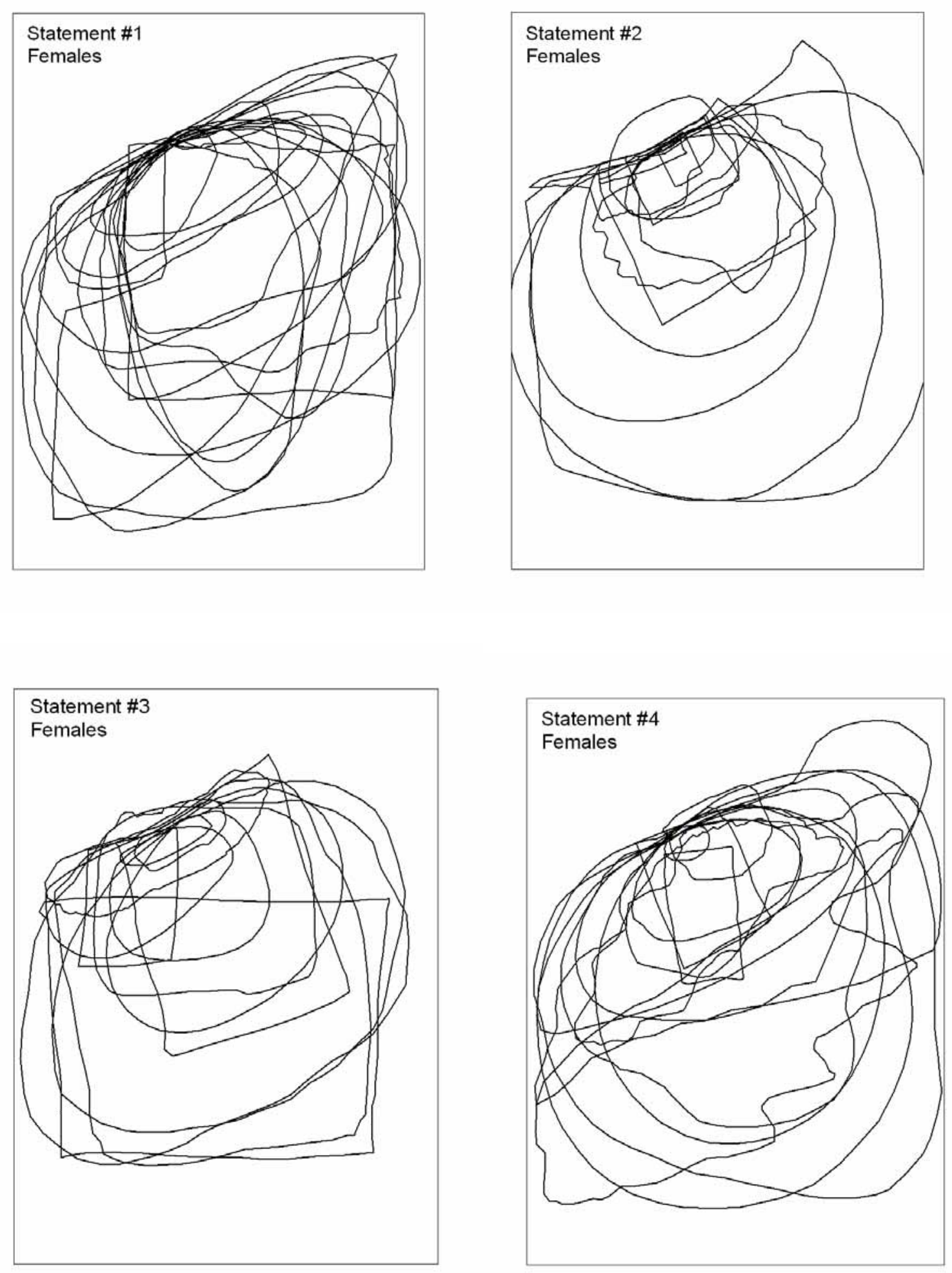

Figure 3 Composites of fire size maps drawn by female participants 

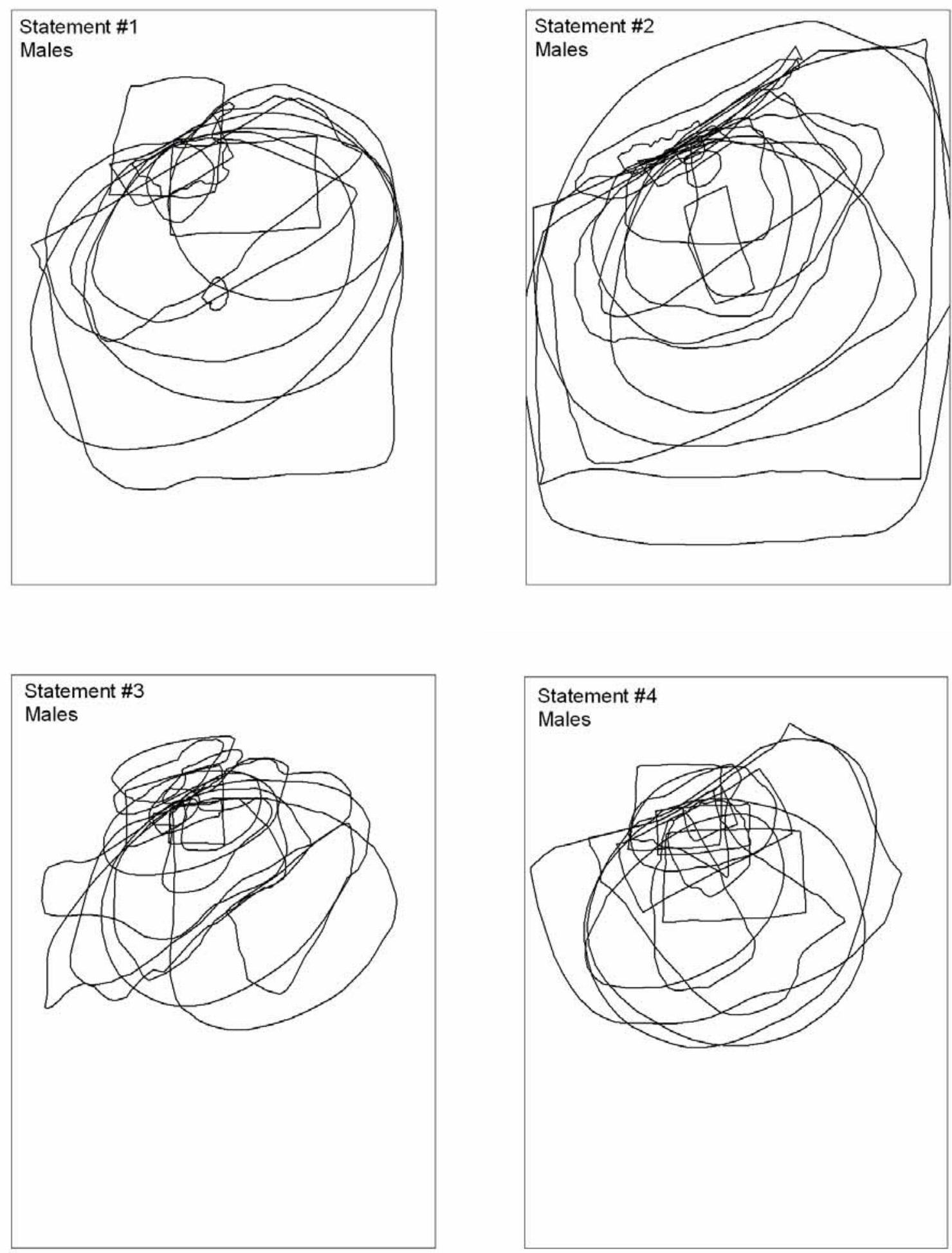

Figure 4 Composites of fire size maps drawn by male participants 
Results indicated that only $16 \%$ of the drawings were within 100 acres of the target size of 370 acres, with $30 \%$ of the maps below 270 acres and $54 \%$ of the maps above 470 acres (Figure 5). The mean response was 979 acres, with a range of 4,281 acres and a standard deviation of 1,024 acres. A one-way ANOVA indicated no significant differences in perceptions of fire size between the groups receiving the four different statements. An independent samples $\mathrm{t}$-test indicated a significant difference between male and female survey respondents $(\mathrm{t}=2.635$, $\mathrm{p}<.01)$. Females drew significantly larger shapes $(x=1230)$ than did males $(x=745)$.
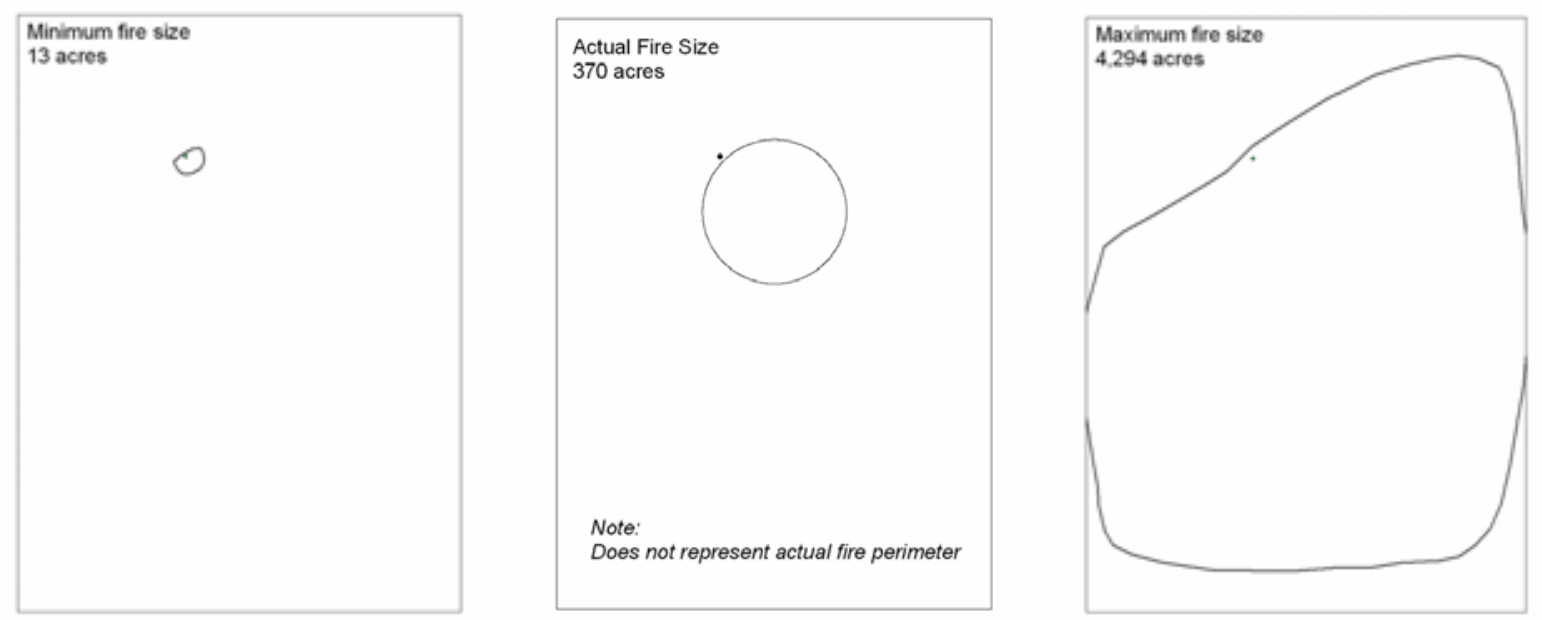

Figure 5 Range of fire size drawings

Visitors were asked about their level of knowledge about the Herman Creek fire prior to the interview. Eighty-four percent chose 3 or less on a semantic differential scale that ranged from 1 (nothing) to 7 (quite a lot); of these $60 \%$ stated they knew nothing about the fire prior to the interview. Participants were asked their attitudes towards the amount of area burned in National Forests and the amount of area burned by the Herman Creek fire. About half of the respondents indicated that the amount of area burned was acceptable in both instances (53\%). Twenty-two percent indicated that fire should be allowed to burn more area in National Forests, but only 7\% stated that the CRGNSA fire should have been allowed to burn more area. 


\section{Discussion}

\section{Schema}

The results of this research may have important implications for the interpretation of natural resources. An understanding of visitors' mental images of National Forests can provide a starting point for designing interpretive media and programs. For instance, the spatial characteristic of trees that was mentioned most often was Species Composition. Interpretation can emphasize the less thought of characteristics of vertical structure and spatial distribution, which can affect the diversity of species. As another example, less than half of the participants indicated that they were thinking of a forest environment on a landscape scale. Geographic interpretation can be used to help people identify with larger spaces, recognize patterns in the landscape, and find meaning in broader environments. A discussion of each of the closed-ended questions regarding the spatial structure of forests follows:

Place or region that comes to mind - Most people (60\%) were thinking in general or regional terms about their mental image of a national forest. Of the $40 \%$ who named a specific place, almost half of those named a National Park instead of a National Forest. The very different missions of the two agencies create two very different types of landscapes - visitors may need more interpretation on this subject to help them differentiate the two. For instance, the multiple-use philosophy of the National Forest Service results in zoning practices that may create different spatial patterns than is found in National Parks.

Tree size - Only $6 \%$ of the survey participants indicated that they imagined primarily small diameter trees. People imagined at least some older growth trees, and therefore may not expect to see large stands of new growth trees. This may have important management implications for western forests in terms of thinning and harvesting practices. 
Undergrowth - Eighty percent of the participants imagined dense undergrowth. The Pacific Northwest is a lush region and may account for this; however, only $35 \%$ of the participants claimed to have been thinking of the Pacific Northwest. Perhaps this indicates visitors have grown accustomed to the condition of the forests due to a century of fire suppression. This does not necessarily mean that visitors desire this condition. Scenic quality research has repeatedly found that visitors prefer forested areas that are somewhat clear beneath the trees (Taylor and Daniel, 1985; Scott, 1998).

Species composition - The majority of people imagined diversity in the number of species of trees. This was also the characteristic of trees that was most mentioned in response to the open-ended question concerning mental images of National Forests. This knowledge can provide interpreters a starting point for helping visitors refine their schema representations of National Forests. For instance, ecological disturbances such as fire can lead to changes in the composition of the landscape that encourages the diversification of species (Perry, 2002).

Forest pattern / Fire effects - The interesting thing about these two questions is that the responses were almost exactly the reverse of the other. About $65 \%$ of people thought that groups of trees would survive a fire, yet about $65 \%$ expected to see continuous forests. Many of the participants indicated that they associated open areas with clearcuts and thus responded negatively to the idea of a patchwork pattern. Visitors may thus need more interpretation on the subject of forest patterns to help them recognize that forest openings provide habitat, fire breaks and meadows for human enjoyment (Perry, 2002). 


\section{Fire Size Maps}

A number of interesting observations can be made regarding the way visitors responded to the mapping task. These observations may identify potential spatial deficiencies of visitors that could be addressed through interpretation. For example, none of the participants expressed difficulty in understanding the air photo, but although the scale bar was pointed out to them, quite a few stated that they forgot about it or did not think to use it while completing the task. Visitors may be unpracticed in using certain map features and need help remembering or learning map-reading skills. For instance, road maps often indicate the mileage for road segments between points on a map, making it unnecessary for people to use scale bars. In addition, while tools like MapQuest make it easier to travel from point A to point B, they discourage the development of spatial skills such as map reading. Interpretation may be able to help visitors develop their map reading skills and thus their sense of space.

A number of other observations are worth noting. While the air photo seemed to be easily understood, the map of the CRGNSA seemed to confuse some visitors. Towns and development within the CRGNSA were represented on the map by the color gray. Some people asked if the Herman Creek fire was represented by one of these gray areas. This illustrates people's tendency to interpret map color as true color (Shemyakin, 1962; Reid, 1989), an important consideration in map design. Additionally, a few people did not start their drawings at the point indicated on the air photo, choosing instead to draw around the dot or in an altogether different part of the map. Still others were clearly influenced by the map frame, creating drawings that encompassed the entire portion of the landscape portrayed by the map. These decisions may have inadvertently influenced the size of their drawings. 
Analysis of the size of the drawings indicated no significant differences between the four groups receiving the different statements regarding fire size. People's difficulty in understanding acreage resulted in a rather random set of drawings that seemed to be primarily based on guessing. While it was assumed that the neutral statement would result in the smallest drawings, the opposite appears to have been true. This may be due to the artificiality of the statements combined with the way people approached the task. The language did seem to have at least some impact on response, for many people verbalized that they were pondering the language. In two instances, visitors drew their response on the map, reconsidered the statement, crossed out the original drawing, and then drew a larger shape (see Figure 6).
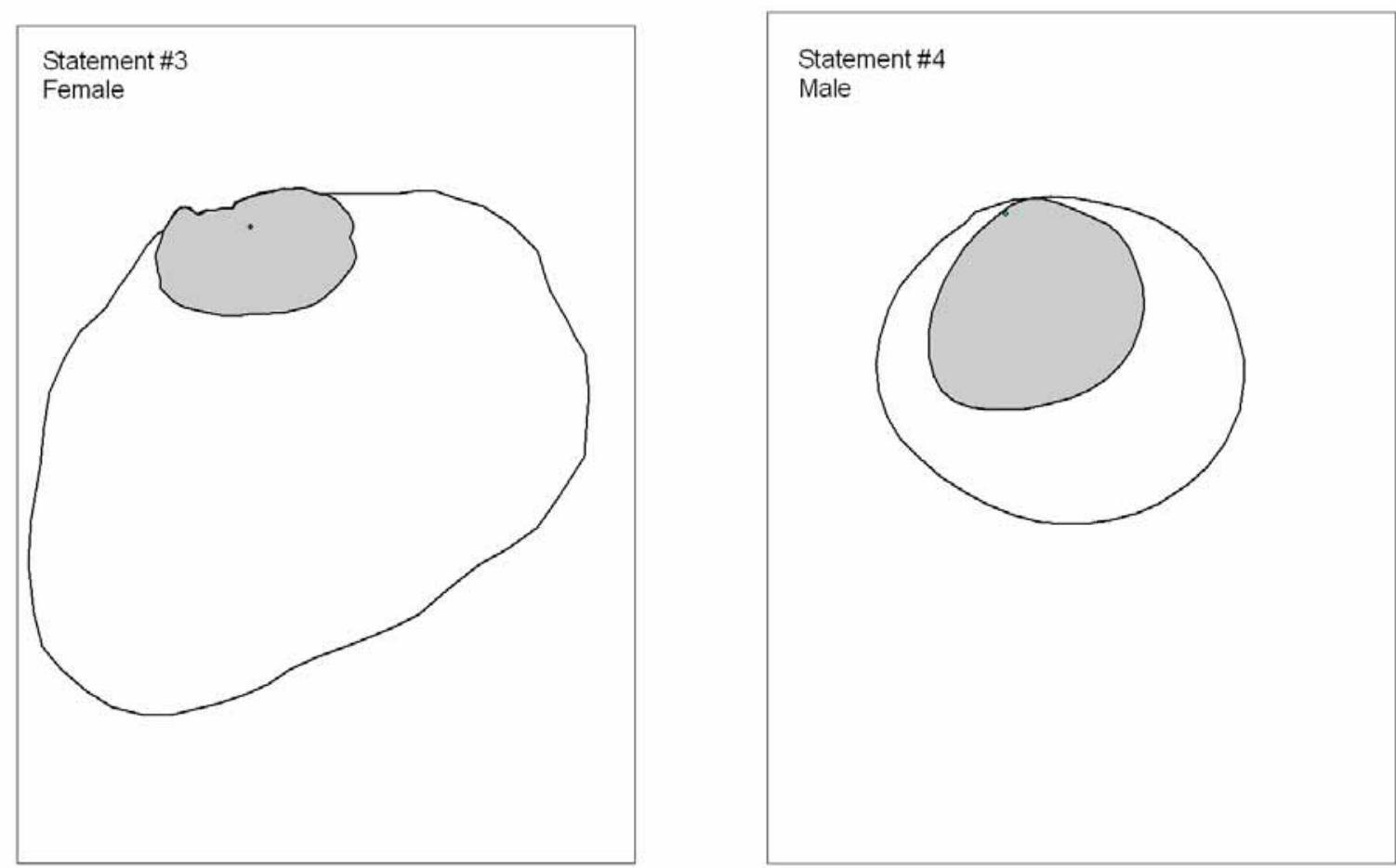

Figure 6 Effect of language on fire size drawings for two participants 
The way visitors approached the task seemed to influence the drawings more so than the language. Those who haphazardly guessed seemed to draw larger shapes, while those that attempted to make educated guesses seemed to draw smaller shapes. The fact that some people verbally pondered the language, suggests that the participants receiving the non-neutral statements may have been aware that they were being tested on their response to the language. They may have therefore spent a little more time considering their response, resulting in smaller shapes. Thus, the stand-alone statements were too artificial and may have influenced the way people approached the task more so than their impressions of the size of the fire. A future study might consider reactions of people to language within an actual or simulated newspaper article, especially if is presented while a fire is actually burning.

For the mapping task, the difference in estimated fire size between male and female participants proved to be significant. The drawings completed by males were significantly smaller $(x=745$ acres) than those completed by females ( $x=1230$ acres). But the responses from both groups varied considerably, with the standard deviation for males being 936 acres and the standard deviation for females being 1063 acres. The high degree of guessing among both male and female participants suggests that lack of spatial knowledge was present in both groups. This finding supports the literature indicating that the size of wildland fires is consistently misunderstood by the public (Cortner et.al., 1984; McCool \& Stankey, 1986; Taylor, 1990; Carpenter et.al., 1986; Taylor \& Mutch, 1986).

As mentioned previously, the way visitors approached the task seemed to influence the size of the drawings. Only a few males and one female verbalized knowledge of the relationship between acres and miles ( 640 acres $=1$ square mile). These individuals used this knowledge to estimate the size of the fire by referring to the scale bar. The rest of the participants appeared to 
be guessing as they completed the task. Many females seemed to lack confidence in their ability to complete the task ("I don't think I'm very good with this sort of thing." "My husband would probably be better at this than me.”). This lack of confidence seemed to lead to more haphazard guessing. Many males, on the other hand, seemed to think they should be able to complete the task. They appeared to spend more time attempting to make an educated guess.

Whether male/female differences are biological or experiential, both sexes can benefit from spatial learning activities (National Research Council, 2006). Interpretation may provide a venue for people to build confidence in their spatial skills in a fun and interactive way. Since it may be more challenging to engage certain people in spatial activities, interactive geographic interpretation could be designed to encourage the participation of multiple people simultaneously. This would prevent one type of person from always engaging in spatial activities while excluding those that may not be initially inclined to participate. This is supported by the research conducted by Paris (1997) and others that indicates visitor learning is benefited by social interaction.

A consideration of the tactics visitors employed to accomplish the mapping task may provide valuable insight into interpretive techniques. The methods most often employed by people to make educated guesses included making a comparison with a place they were familiar with (i.e. acreage of personal property or local park) and seeking out landscape clues to predict the spread of the fire. Since these are techniques that are already employed by visitors, interpretation can be used to help people find visual clues in the landscape (Vander Stoep, 1990) and to incorporate previous experiences (Ham, 1992). The shapes of the drawings appeared to be directly related to the way visitors approached the task. Those using the scale bar typically drew rectangles, haphazard guessers drew circular shapes, and those using landscape clues drew 
irregular shapes. Since those using the scale bar drew rectangular shapes, designing scale bars that portray area units rather than linear units may be an effective technique.

The question concerning attitudes towards the amount of area burned did not produce useful results because most people seemed to pick the safe or more neutral answer (Fires have burned an acceptable amount of area). This indicates that participants may have been uncomfortable making a judgment. As other researchers have indicated, there are a range of situational influences that affect people's attitude towards fire (Kneeshaw et.al., 2004). People in this study felt that being prompted with only information regarding the amount of area burned was too simplistic. Many asked questions about other factors such as the source of ignition, the amount of damage to life and property, and the percentage of the CRGNSA that was burned. People were conflicted on this question, indicating that they now understand that fire plays a role in forest ecology. The change of scale between National Forests and the CRGNSA did prompt a few people to select a different answer. Some people were slightly less accepting of the amount of area burned by the Herman Creek fire than National Forest fires in general. 


\section{Conclusions and Recommendations}

\section{Conclusions}

The National Research Council (2006) recently published a 300-page report on Learning to Think Spatially. This in-depth report identified a need for increased spatial literacy and recommended the incorporation of spatial learning in the K-12 curriculum. The Council recognized spatial thinking as one of the many forms of cognition that includes verbal and mathematical thinking - the current focus of curriculum in the United States. Given that the educational system is just now pondering the addition of spatial learning to the curriculum, the field of interpretation has an opportunity to be on the cutting edge of this new development. Recognizing geointerpretation as a growing subfield and embracing the possibilities it offers will prove timely indeed.

Thus, geointerpretation is here defined as interpretation that provides opportunities to experience large-scale environments through the use of maps and other spatial representations. In addition, sense of space is here defined as an understanding of the meaning derived from the spatial relationships of places. The goal of geointerpretation is thus to foster a sense of space in the minds of visitors and the public. The principles of geointerpretation as outlined in this paper are as follows: 1) to guide people through the declarative, procedural, and configurational levels of spatial knowledge (Golledge \& Stimson, 1997), and 2) to design maps and other spatial representations as though they are exhibits - considering type, theme, levels, design, text, visuals and interaction (Ham, 1992). Natural resource interpretation can thus be enhanced by connecting people to the meanings of large-scale environments. 


\section{Recommendations}

The overall recommendation is to replicate this research using larger sample sizes and to perform further studies of visitors' mental images of large landscapes and their perceptions of the size of large areas. Additionally, studies need to be conducted to test the effectiveness of the geographic interpretation techniques suggested in this thesis. The following specific recommendations are also made:

\section{$\underline{\text { Based on Literature Review }}$}

Design geographic interpretation around the three components of spatial knowledge: locations, routes, and areas (Shemyakin, 1962; Golledge \& Spector, 1978). Maps can easily be broken down into their key components using a series of side-by-side maps and models that can be viewed sequentially or using a set of overlays that can be layered on top of one another. There are many ways to accomplish this, ranging from using very simple and inexpensive props to highly technical computerized wall displays. The key is to enable the visitor to learn sequentially, starting with a few key locations, then adding significant paths or other linkages, and finally introducing more abstract information such as watershed boundaries, fire regimes or habitat corridors. This progression will allow visitors to construct a mental map through a simple step-by-step process. This method also provides a ready-made framework for designing interpretive programs around maps and models. This technique may significantly enhance interpretation of the way large landscapes affect natural processes, historical events, and even economic or political occurrences.

Use geointerpretation to provide visitors with multiple opportunities to learn about an environment (Golledge, 1992; Peuquet, 2002). Multiple experiences can serve a dual role of helping visitors improve environmental learning while also increasing spatial ability and map 
reading skills. An entire exhibit room devoted to geointerpretation would by the ideal - offering multiple interactive opportunities for visitors to experience a space. Some examples include: 1) floor or table-top base maps with props and toys that allow visitors to create their own maps; 2) a computer screen connected to Google Earth that allows visitors to travel through virtual space; 3 ) games and puzzles that require visitors to perform spatial tasks such as mental rotation (i.e. from birds-eye to side view) and to use map features (i.e. scale bars, legends); and 4) activities like scavenger hunts and geocaching that encourages direct interaction with the environment. A strong focus on geographic interpretation at the beginning of a visit may allow for faster orientation to the site and provide a spatial context for subsequent experiences. In the end, geointerpretation may have the potential to significantly increase a visitor's understanding of the site as a whole.

Design all maps and other spatial representations as though they are exhibits considering type, theme, levels, design, text, visuals and interaction (Ham, 1992). These seven elements provide a framework that can be used in the planning and design of all geointerpretation. Maps are highly complex, yet their design can be greatly simplified by following this step-by-step process. Ideally, the framework could provide the basis for an entire handbook or guidebook devoted to the subject of geointerpretation. Interpretive personnel would benefit from training seminars on how to apply this framework and incorporate spatial learning into their exhibits and programs.

\section{Based on Visitor Study}

When describing the size of areas, relate unfamiliar spatial units (such as acres) to the prior knowledge of the visitor (Ham, 1992). Descriptions of the size of natural areas are typically provided in acres. Yet as fewer and fewer people come from farming, ranching or other 
rural backgrounds, this spatial unit has become less and less familiar. Comparing acres to more common units of measurement (such as square miles) may help visitors to relate the two.

Similarly, using analogies such as city blocks or football fields may be useful in visualizing the size of an acre of land. Another technique might be to design scale bars that portray area units rather than linear units. For instance, a series of squares depicting 1, 10, 100 and 1000 acres. Interpretive maps need not follow stringent mapping conventions as long as scale is maintained and the map is not misleading. In fact, interpretation provides an opportunity for map-makers to express a little creativity.

Help visitors refine schema representations by interpreting the differences between National Forests and National Parks (Medyckyj-Scott \& Blades, 1992; Peuquet, 2002). Visitors may understandably be confused with the myriad types of protected areas that may all be present in a single region. National Forests, National Parks, Wilderness areas, wild and scenic rivers, state parks and private recreation areas may even be adjacent to one another, making it difficult to differentiate one from the other. Many sites only interpret the area within their boundaries. These administrative boundaries are highly superficial and are likely to be indiscernible to most visitors. Interpreting the surrounding spaces may provide visitors with a holistic and more realistic view of the area. In addition, the varying missions of the different agencies can drastically affect the layout of a landscape. For instance, the various zones within a National Forest result in a different type of landscape than the single-use philosophy of the National Parks. Yet, if visitors don't understand these differences, their mental image of one type of protected area may be influenced by another. While the philosophies that guide the management of an area may be highly controversial, interpreting protected areas as different types of spaces may provide a more neutral alternative. 
Target women in fire information and geographic interpretation programs (Cortner, et.al., 1984; Taylor \& Mutch, 1986, Lajoie, 2003). While targeting a specific group is difficult in interpretation, certain techniques can be used to meet the spatial learning needs all visitors. Women (and certainly many men) may not initially be interested in geographic interpretation or inclined to engage in spatial activities. Designing games and activities that require the participation of multiple people simultaneously may encourage the reluctant visitor to join in. Similarly, analogies used to increase understanding of spatial units should not be restricted to a single example. For instance, football fields may not be a familiar frame of reference for all visitors. Other examples - such as a city block, shopping center, or playground - can also be used for comparison. Offering geography or map-skills sessions for women or parents and children may be another way to facilitate spatial learning for targeted groups.

Interpret the positive aspects of forest openings and patterns (McCool \& Stankey, 1986). Just as Smokey Bear created an overwhelming aversion to fire in the American psyche, so too have clear-cutting practices instilled a distaste for open areas in forest landscapes. Forest openings can also be created by natural processes, providing habitat, fire breaks, and scenic views. Interpreting the spatial variations in the landscape may help visitors think of forests as a colorful quilt rather than as a homogeneous blanket of trees. The results of this study suggested that people may be inclined to think of species composition rather than spatial characteristics such as the distribution of trees. Interpretation can draw a link between the number of species and the spatial arrangement of trees - providing a bridge between the interests of the visitor and a new meaning of the resource. 


\section{References}

Abel, R.R., \& Kulhavy, R.W. (1986). Maps, mode of text presentation, and children's prose learning. American Educational Research Journal, 23(2), 263-274.

Andrews S.K. (1983). Spatial cognition through tactual maps. Proceedings of the 1st international symposium on maps and graphics for the visually handicapped. Association of American Geographers, 30-40.

Arno, S.F., \& Allison-Bunnell, S. (2002). Flames in Our Forest, Washington: Island Press.

Arthur, P., \& Passini, R. (1992). Wayfinding: People, Signs, and Architecture. New York: McGraw-Hill Book Company.

Basman, C.M. (2003). Bibliography of interpretive resources. Journal of Interpretation Research, 8(2), $164 \mathrm{p}$.

Bertin, J. (1981). Graphics and Graphic Information-Processing. Berlin: de Gruyter.

Billing, J.C. (1993). Can fire policy enhance scenic value and public perception? Renewable Resources Journal Special Report, (Spring), 27.

Bremen, G., Albrecht, B., Dale, M., \& Hertel, E. (1992). The living map: Bridging the gap. 1992 National Interpreters Workshop Proceedings, 216-219.

Carpenter, E.H., Taylor, J.G., Cortner, H.J., Gardner, P.D., Zwolinski, M.J., \& Daniel, T.C. (1986). Targeting audiences and content for forest fire information programs. Journal of Environmental Education, 17(3), 33-41.

Cheng, A.S. \& Daniels, S.E. (2003). Examining the interaction between geographic scale and ways of knowing in ecosystem management: A case study of place-based collaborative planning. Forest Science, 49(6), 841-854.

Chou, Y.H. (1997). Exploring Spatial Analysis in Geographic Information Systems. Santa Fe: Onword Press.

Clebsch, J.C., \& Curwen, J. (2000). GIS-Geographic Information Systems and Good Interpretive Services. 2000 Interpretive Sourcebook, 207-209.

Cortner, H.J., Zwolinski, M.J., Carpenter, E.H., \& Taylor, J.G. (1984). Public support for firemanagement policies. Journal of Forestry, 82 (6), 359-361.

Cresswell, T. (2004). Place: A Short Introduction. Malden, MA: Blackwell Publishing. 
Denhiere, G., \& Denis, M. (1989). The processing of texts describing spatial configurations. In Mandl, H., Levin, J.R. (Eds), Knowledge Acquisition from Text and Pictures. Amsterdam: Elsevier, pp. 249-260.

Downs, R., \& Stea, D. (1977). Maps in Minds: Reflections on Cognitive Mapping. New York: Harper and Row.

Dransch D. (2000). The use of different media in visualizing spatial data, Computers \& Geosciences, 26(1), 5-9.

Dwyer, J.F., \& Childs, G.M. (2003). Movement of people across the landscape: a blurring of distinctions between areas, interests, and issues affecting natural resource management. Landscape and Urban Planning, 69, 153-164.

Englin, J., Loomis, J., \& Gonzalez-Caban, A. (2001). The dynamic path of recreational values following a forest fire: a comparative analysis of states in the Intermountain West. Canadian Journal of Forest Research, 31(10), 1837-1844.

Evans, C., Butcher, G., Dufficy, T., \& Hamel, C. (1999). From a bird's-eye view to satellite images - changing views of your park. 1999 Interpretive Sourcebook, 73-76.

Freundschuh, S.M., \& Egenhofer, M.J. (1997). Human conceptions of spaces: implications for GIS. Transactions in GIS, 2(4), 361-375.

Galliano, S.J., \& Loeffler, G.M. (1999). Place assessment: How people define ecosystems. USDA Forest Service General Technical Report PNW, 462 (Sept), 31p.

Gardner, P.D., Cortner, H.J., \& Widaman, K.F. (1985). Forest-user attitudes toward alternative fire management policies. Journal of Environmental Management, 9(4), 303-312.

Golledge, R.G. (1992). Place recognition and wayfinding: Making sense of space. Geoforum, 23(2), 199-214.

Golledge, R.G., \& Spector, A. (1978). Comprehending the urban environment: Theory and practice. Geographical Analysis, 10, 403-426.

Golledge, R.G., \& Stimson, R.J. (1997). Spatial Behavior: A Geographic Perspective. New York: Guilford Press.

Gross, M., \& Zimmerman, R. (2002). Interpretive centers: The history, design and development of nature and visitor centers. Stevens Point, WI: UW-SP Foundation Press, Inc.

Guy, B.S., Curtis, W.W., \& Crotts, J.C. (1990). Environmental learning of first-time travelers. Annals of Tourism Research, 17, 419-431. 
Gyllenhaal, E.D., \& Perry, D.L. (1998). Doing something about the weather: Summative evaluation of Science Museum of Minnesota's Atmospheric Explorations computer interactives. Current Trends in Audience Research and Evaluation, 11, 25-35.

Hall, C.M., \& Page, S.J. (2002). The Geography of Tourism and Recreation: Environment, Place and Space, $2^{\text {nd }}$ ed. London \& New York: Routledge.

Ham, S.H. (1992). Environmental Interpretation: A Practical Guide for People with Big Ideas and Small Budgets. Golden, CO: Fulcrum Publishing.

Harmon, K. (2004). You Are Here: Personal Geographies and other Maps of the Imagination. New York: Princeton Architectural Press.

Herman, J.F., Herman, T.G., \& Chatman, S.P. (1983). Constructing cognitive maps from partial information: A demonstrations study with congenitally blind subjects. Journal of Visual Impairment and Blindness, 77(5), 195-198.

Jacobson, R.D. (1998). Cognitive mapping without sight: Four preliminary studies of spatial learning. Journal of Environmental Psychology, 18, 289-305.

Jacobson, S.K., Monroe, M.C., \& Marynowski, S. (2001). Fire at the wildland interface: The influence of experience and mass media on public knowledge, attitudes and behavioral intentions. Wildlife Society Bulletin, 29(3), 929-937.

Kealy, M. (1998). Lost? Don't blame the map: Designing maps for visitors. 1998 Interpretive Sourcebook, 172-174.

Kerski, J.J., \& Reiter, S. (2004). Interpreting the landscape with USGS maps, aerial photographs and GPS. 2004 Interpretive Sourcebook, 138-139.

Kitchin, R.M. (1997). Exploring spatial thought. Environment and Behavior, 29(1), 123-156.

Kneeshaw, K., Vaske, J.J., Bright, A.D., \& Absher, J.D. (2004). Situational influences of acceptable wildland fire management actions. Society and Natural Resources, 17(6), 477-489.

Knopf, R.C. (1981). Cognitive map formation as a tool for facilitating information transfer in interpretive programming. Journal of Leisure Research, 13(3), 232-242.

Lajoie, S.P. (2003). Individual differences in spatial ability: Developing technologies to increase strategy awareness and skills. Educational Psychologist, 38(2), 115-125. 
Lankford, S.V., Scholl, K., Pfister, R., Lankford, J., \& Williams, A. (2004). Cognitive mapping: An application for trail management. Proceedings of the 2004 Northeastern Recreation Research Symposium, 378-384.

Levine, M., Marchon, I., \& Hanley, G. (1984). The placement and misplacement of you-arehere maps. Environment and Behavior 16(2), 139-157.

Littlejohn, M.A., Meldrum, B.H., \& Hollenhorst, S.J. (2006). Yosemite National Park Visitor Study, NPS VSP Report 168, 103 p.

Longley, P., Goodchild, M., Maguire, D, \& Rhind, D. (2005). Geographic Information Systems and Science, $2^{\text {nd }}$ ed. Hoboken, N.J.: John Wiley \& Sons, Ltd.

Loomis, J.B., Bair, L.S., \& Gonzalez-Caban, A. (2001). Prescribed fire and public support: knowledge gained, attitudes changed in Florida. Journal of Forestry, 99(11), 18-22.

Macie, E.A., \& Hermansen, L.A. (2003). Human influences on forest ecosystems. The Southern Wildland-Urban Interface Assessment Summary Report, Forest Service GTR SRS-64.

Manfredo, M.J. (1990). Attitudes toward prescribed fire policies. Journal of Forestry, 88(7), 19-23.

Manning, R.E. (2000). Defining and establishing indicators and standards of quality. In Fulton, D.C., Nelson, K.C., Anderson, D.H., \& Lime, D.W. (Eds.), Human Dimensions of Natural Resource Management: Emerging Issues and Practical Applications. St. Paul: Cooperative Park Studies Program, University of Minnesota, pp. 30-39.

McCool, S.F., \& Stankey, G.H. (1986). Visitor attitudes toward wilderness fire management policy. USDA Forest Service Research Paper INT, 357 (Jan), 1-7.

Medyckyj-Scott, D., \& Blades, M. (1992). Human spatial cognition: Its relevance to the design and use of spatial information systems. Geoforum, 23(2), 215-226.

National Geographic (2006). Geotourism Charter. Retrieved June 10, 2006, from http:// www.nationalgeographic.com/travel/sustainable/.

National Research Council (2006). Learning to Think Spatially. Washington, D.C.: National Academies Press. Also available at http://newton.nap.edu/catalog/11019.html.

Nielsen, C., \& Buchanan, T. (1986). A comparison of the effectiveness of two interpretive programs regarding fire ecology and fire management. Journal of Interpretation Research, 2(1), 1-10. 
Palmer, J.F., \& Sena, K.D. (1992). Seasonal scenic value and forest structure in northeastern hardwood stands. Proceedings of the 1992 Northeastern Recreation Research Symposium, 115-121.

Paris, S.G. (1997). Situated motivation and informal learning. Journal of Museum Education, 22(2), 22-27.

Perry, G.L.W. (2002). Landscapes, space and equilibrium: shifting viewpoints. Progress in Physical Geography, 26(3), 339-359.

Peuquet, D.J. (2002). Representations of Space and Time. New York: Guilford Press.

Redvale, J., \& Dickey, E. (1995). Hands-on exhibits: The magical touch. The 1995 Interpretive Sourcebook, 199-201.

Reid, T.R. (1989). When the press yelled 'fire!' Journal of Forestry, 87(12), 36-37.

Scott, J.H. (1998). Fuel reduction in residential and scenic forests: a comparison of three treatments in a western Montana ponderosa pine stand. USDA Forest Service Research Paper RMRS, 5, 1-19.

Shemyakin, F.N. (1962). General problems of orientation in space and space representations. In B.G. Anan'yev, et al. (Eds.), Psychological Science in the USSR (Vol. 1), NTIS Report No. TT62-11083 (p. 184-225). Washington, DC: Office of Technical Services.

Shindler, B.A., Brunson, M., \& Stankey, G.H. (2002). Social acceptability of forest conditions and management practices: a problem analysis. USDA Forest Service General Technical Report PNW, 537 (May), 68 p.

Spear, D. (1997). The living map as an interactive interpretive tool (or how to create your own living map program). 1997 Interpretive Sourcebook, 107-108.

Spice, B. (2005, September 12). Mapping Katrina's ruins. Pittsburgh Post-Gazette. Retrieved October 10, 2005 from www.post-gazette.com/pg/pp/05255/569722.stm.

Stankey, G.H. (1976). Wilderness fire policy: An investigation of visitor knowledge and beliefs. USDA Forest Service Research Paper INT, 180, 1-17.

Taylor, J.G. (1990). Playing with fire: effects of fire in management of southwestern recreation resources. USDA Forest Service General Technical Report RM, 191, 112-122.

Taylor, J.G., \& Daniel, T.C. (1985). Perceived scenic and recreational quality of forest burn areas. USDA Forest Service General Technical Report INT, 182 (April), 398-406. 
Taylor, J.G., \& Mutch, R.W. (1986). Fire in wilderness: Public knowledge, acceptance and perceptions. In Proceedings - National Wilderness Research Conference: Current Research. USDA Forest Service INT, 49-59.

Thorndyke, P.W., \& Stasz, C. (1980). Individual differences in procedures for knowledge acquisition from maps. Cognitive Psychology, 12, 137-175.

Toman, E., Shindler, B., \& Reed, M. (2004). Prescribed fire: the influence of site visits on citizen attitudes. Journal of Environmental Education, 35(3), 13-17.

U.S. Forest Service, (2001). Caring for Your Forests with a Forest Stewardship Plan, FS-661 (March), 10p.

Uzzell, D., Pol, E., \& Badenas, D. (2002). Place identification, social cohesion, and environmental sustainability. Environment and Behavior, 34(1), 26-53.

Vander Stoep, G.A. (1990). Aerial photos and other views from above: New ways to tell old stories. 1990 National Interpreters Workshop Proceedings, 92-94.

Vaux, H.J. Jr., Gardner, P.D., \& Mills, T.J. (1984). Methods for assessing the impact of fire on forest recreation. USDA Forest Service General Technical Report PSW, 79, 1-13.

Wall, G. (1997). Tourism attractions: Points, lines, and areas. Research Notes and Reports, Annals of Tourism Research, 24(1), 240-243.

Warren, D.H., \& Scott, T.E. (1993). Map alignment in traveling multisegment routes. Environment and Behavior, 25(5), 643-666.

Winter, G., \& Fried, J.S. (2000). Homeowner perspectives on fire hazard, responsibility, and management strategies at the Wildland-Urban Interface. Society \& Natural Resources, $13,33-49$.

Winter, G., Vogt, C.A., \& McCaffrey, S. (2004). Examining social trust in fuels management strategies. Journal of Forestry, (Sept), 8-15.

Young, M. (1999). Cognitive maps of nature-based tourists. Annals of Tourism Research, 26(4), 817-839. 


\section{Appendix}

\section{Questionnaire}

\section{When you hear the phrase "National Forest" - what image forms in your mind?}

A) Please describe this mental picture in detail.

Interviewer Prompts (if visitor has difficulty answering question):

Pretend you are explaining what a National Forest looks like to someone who has never seen one Imagine you are looking at a photograph of a national forest-describe what you see Please describe the physical characteristics of a national forest

B) Were you thinking of a specific place or region? Yes No

If yes, what is this place?

\section{Please answer the following questions about the forest landscape that you described in question number 1:}

A) In the forest that you imagine, what size are the trees?

The forest has mostly large diameter trees

The forest has an equal mix of large and small diameter trees

The forest has mostly small diameter trees

B) In the forest that you imagine, what does the space between the trees look like?

The space between the trees is mostly clear of live and dead vegetation

The space between the trees is full of live and dead vegetation

C) How many species of trees do you imagine?

The forest has mainly one type of tree

The forest has a fairly equal mix of two or more types of trees

3. Now imagine that you are looking down at the forest landscape that you described in question number 1. Picture how it looks from above, as if you are looking at it from a small airplane. Form a clear image of this landscape in your mind before answering the following questions:

A) What type of pattern do the trees form?

The forest is mostly continuous, with few breaks in the trees

The forest is a patchwork of trees and open areas

B) Picture the forest after a fire - what do the trees look like?

Most of the trees appear to have been killed by the fire

Many groups of trees appear to have survived the fire 
4. Choose the statement that most closely matches your own personal opinion about fires in National Forests over the last 20 years:

Any amount of fire in the National Forests is unacceptable

Fires have been allowed to burn too much area in National Forests

Fires have burned an acceptable amount of area in National Forests

Fires should be allowed to burn more area in National Forests

Interviewer:

Tell Participant: "The following questions are about the Columbia River Gorge National Scenic Area, which you are visiting now."

Show participant prompt card with the CRGNSA map and ask him/her to read the statement on the card.

5. [Show participant map of Herman Creek area.] This is an aerial photograph of the Herman Creek area. Starting at the black dot, draw an outline to show your perception of the size of the Herman Creek fire.

6. How much did you know about the Herman Creek fire prior to this interview?

nothing

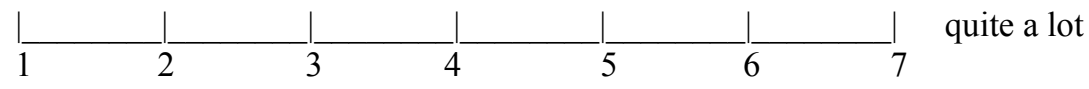

7. How did you first learn of the fire in the Herman Creek area? Please choose only one.

Public media - place a checkmark $(\sqrt{ })$ next to one of the following: newspaper __ magazine __ television __ radio __ internet

Government representative

Visitor / Interpretive center display

Forest Service documents or publications

This survey

8. If you were aware of the Herman Creek fire while it was burning, please rate the availability of information during the fire. Information was:

Not Applicable

difficult to obtain

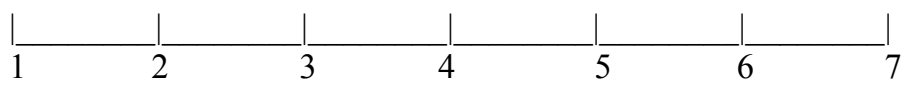

very easy to find

not provided in a timely manner

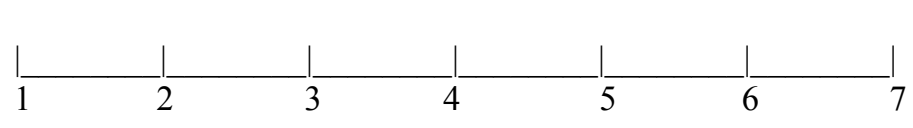

provided in a very timely manner

hard to understand
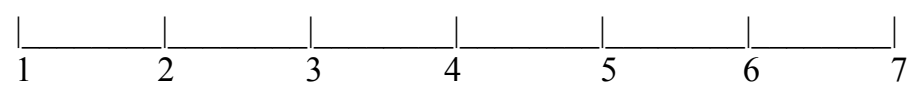

easy to understand

9. Choose the statement that most closely matches your own personal opinion about the fire that occurred in the Herman Creek area in 2003.

Any amount of fire in the Columbia River Gorge National Scenic Area is unacceptable

The fire was allowed to burn too much of the Columbia River Gorge National Scenic Area

The fire burned an acceptable amount of the Columbia River Gorge National Scenic Area

_ The fire should have been allowed to burn more of the Columbia River Gorge National Scenic Area 


\section{In 2003, the immense Herman Creek Fire burned through 370 acres of the Columbia River Gorge National Scenic Area.}

\section{Columbia River Gorge National Scenic Area}
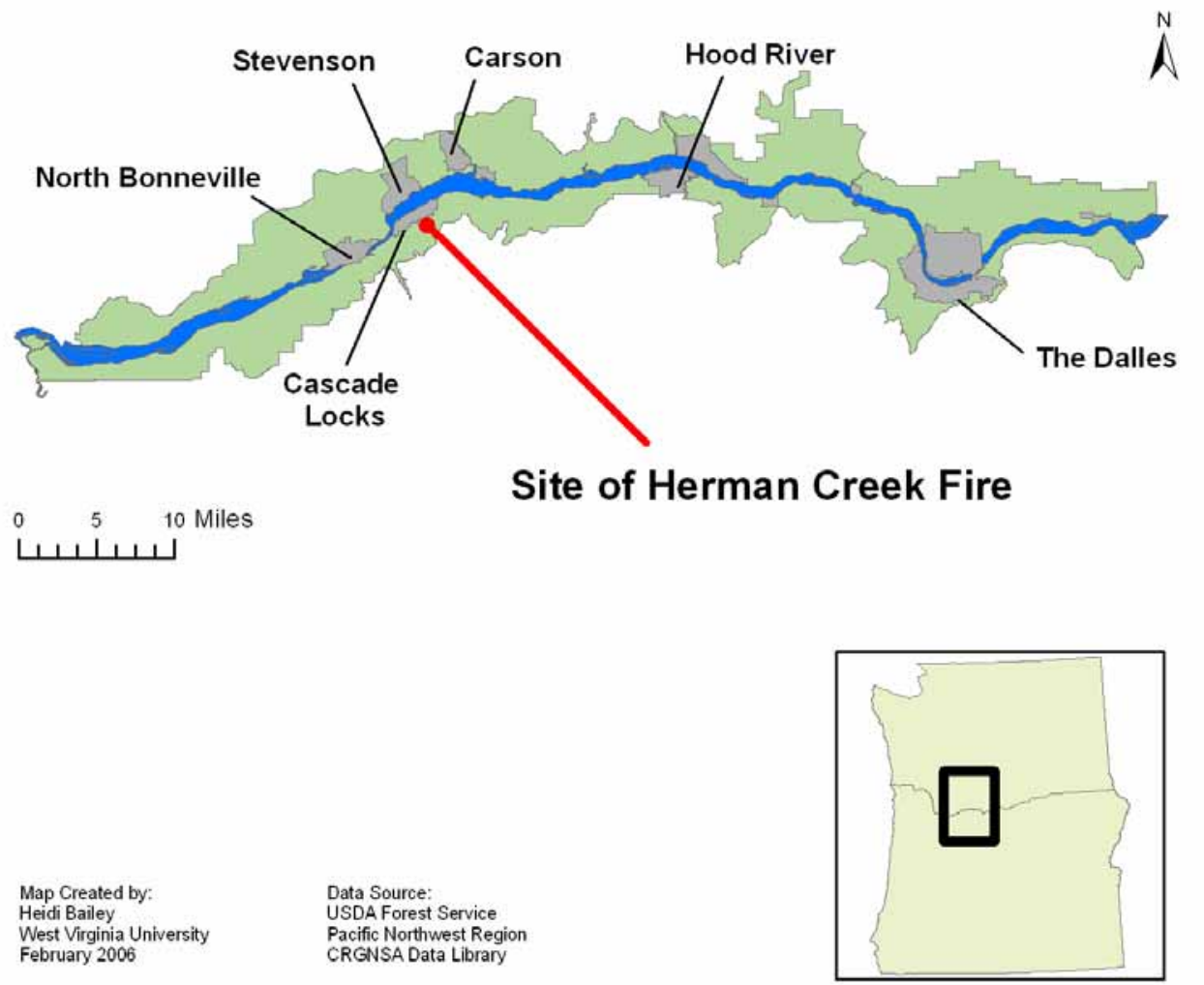
The Herman Creek Area Prior to the Fire of 2003
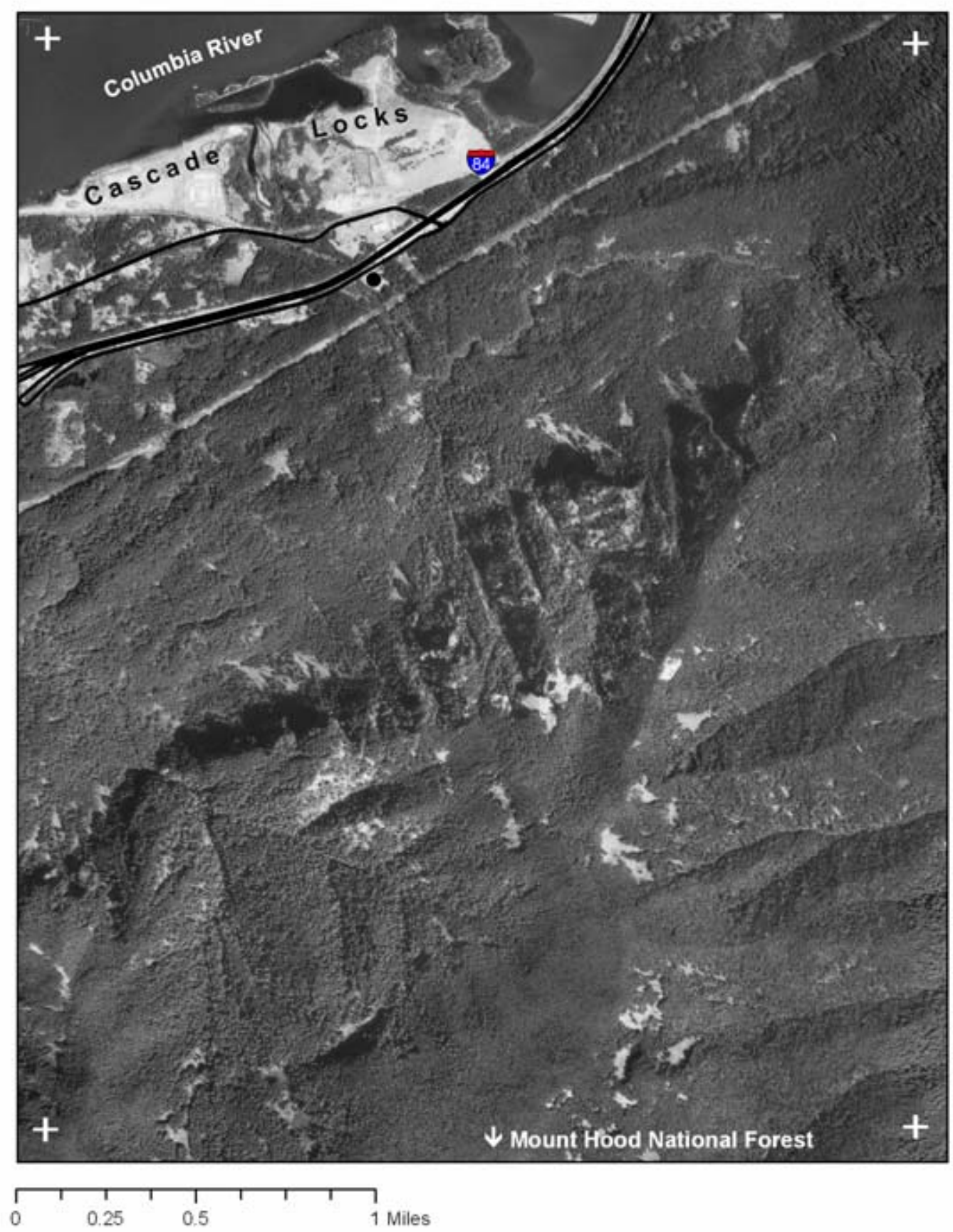

Map Created by: Heidi Bailey

West Virginia Universty

February 2006
Data Source:

Oregon Geospatial

Data Clearinghouse 